\title{
The functionally unannotated proteome of
}

\author{
human male tissues: a shared resource to
}

uncover new protein functions associated with

reproductive biology.

Yves Vandenbrouck ${ }^{1, *}$, Charles Pineau ${ }^{2}$, Lydie Lane ${ }^{3}$

1. Univ. Grenoble Alpes, INSERM, CEA, IRIG-BGE, U1038, 38000, Grenoble, France

2. Univ. Rennes, Inserm, EHESP, Irset (Institut de recherche en santé, environnement et travail) - UMR_S 1085, F-35042 Rennes cedex, France

3. SIB Swiss Institute of Bioinformatics and Department of microbiology and molecular medicine, Faculty of medicine, University of Geneva, CMU, Michel Servet 1, 1211 Geneva 4, Switzerland

* To whom correspondence should be addressed: yves.vandenbrouck@cea.fr 


\begin{abstract}
In the context of the Human Proteome Project, we built an inventory of 412 functionally unannotated human proteins for which experimental evidence at the protein level exist (uPE1) and which are highly expressed in tissues involved in human male reproduction. We implemented a strategy combining literature mining, bioinformatics tools to collate annotation and experimental information from specific molecular public resources, and efficient visualization tools to put these unknown proteins into their biological context (protein complexes, tissue and subcellular location, expression pattern). The gathered knowledge allowed pinpointing five uPE1 for which a function has recently been proposed and which should be updated in protein knowledge bases. Furthermore, this bioinformatics strategy allowed to build new functional hypotheses for five other uPE1s in link with phenotypic traits that are specific to male reproductive function such as ciliogenesis/flagellum formation in germ cells (CCDC112 and TEX9), chromatin remodeling (C3orf62) and spermatozoon maturation (CCDC183). We also discussed the enigmatic case of MAGEB proteins, a cancer/testis antigen subtype poorly documented. Tools used and computational outputs produced during this study are freely accessible via ProteoRE (http://www.proteore.org), a Galaxy-based instance, for reuse purposes. We propose these five uPE1s should be investigated in priority by expert laboratories and hope that this inventory and shared resources will stimulate the interest of the community of reproductive biology.
\end{abstract}

KEYWORDS: human proteome project, proteomics, male reproduction, functionally unannotated proteins, bioinformatics, biocuration, data mining, protein complexes, protein interaction networks, ciliogenesis, spermatogenesis, acrosome, chromatin remodeling, cancer/testis antigens. 


\section{INTRODUCTION}

The HUPO Human Proteome Project (HPP) recently launched a new initiative, nextCP50, aiming to fill the gaps in the functional annotation of the human proteome ${ }^{1}$. Thanks to the continuous effort of the life science community, the number of proteins devoid of functional annotations - derived from bioinformatics prediction or from experimental studies, is constantly decreasing. Although they are functionally unannotated, these proteins can have other types of annotations such as subcellular locations, protein-protein interactions, tissue expression, association with diseases or 3D structure. This information can be examined using the advanced search functionality of neXtProt ${ }^{2}$. In addition, neXtProt provides a "protein existence" (PE) status to each entry, which indicates the type of evidence that supports the existence of the protein. The value 'Experimental evidence at protein level' (PE1) indicates that there is clear experimental evidence for the existence of at least one proteoform in the entry. The value 'Experimental evidence at transcript level' (PE2) indicates that the existence of a protein has not been proven but that expression data indicate the existence of a transcript. The value 'Protein inferred by homology' (PE3) indicates that the existence of a protein is probable because clear orthologs exist in closely related species. The value 'Protein predicted' (PE4) is used for entries without evidence at protein, transcript, or homology levels. Finally, the value 'Protein uncertain' (PE5) indicates that the existence of the protein is unsure and that it most probably corresponds to an incorrect in silico translation of a non-coding element. In neXtProt 2020-01-17, there are 1,813 PE1-4 proteins with no function annotated. Among them, 559 have not been confidently detected at protein level in a human sample and are considered as "missing" (PE2-4), whereas 1254 have been experimentally verified (PE1) and are called "uPE1" . The present study focuses on the uPE1 proteins whose expression is elevated in the male reproductive system. We included in our analysis the testis, epididymis, vas (ductus) deferens, seminal vesicle and prostate. The function of the male reproductive system is to produce male gamete - spermatozoa 
- and transfer them to the female reproductive tract. The testis is a crucial component in this process, as it produces both spermatozoa and androgens that support male reproductive physiology. Accessory organs and ducts also contribute to sperm maturation and transport mainly through the production of the seminal plasma, a complex biological fluid that originates from the testes $(1-2 \%)$, the epididymis $(2-4 \%)$, the seminal vesicles $(65-75 \%)$, the prostate gland $(25-30 \%)$ and the bulbourethral or Cowper's gland $(<1 \%)$. The seminal plasma, in addition to its obvious role in sperm transportation, provides a nutritive and protective milieu and is involved in the final maturation of the male gametes ${ }^{4}$. Previous transcriptomics and proteomics studies revealed that the human testis displays the largest number of tissue-enriched genes followed by the brain and liver ${ }^{5-8}$. The large number of enriched genes in testis is considered to be due to the highly specialized processes occurring during spermatogenesis that are linked to the presence of the germ cell lineage. Conversely a significant number of enriched genes is present in the epididymis, and to a lesser extent some can also be found in seminal vesicle and prostate; organs that are known to be involved in the post-testicular maturation of spermatozoa. In the present study we established an inventory of $412 \mathrm{uPE} 1$ proteins enriched in the male reproductive system by collating information (e.g., experimental data, annotation, facts from literature) from publicly available resources. Then, we built functional hypotheses on a small set of these functionally unannotated protein entries by: i. combining contextual information (molecular complexes, cellular localization, expression level), ii. visualizing the resulting protein complexes, and iii. documenting their likelihood by cross-checking with the literature and our own knowledge. The datasets and tools used in this study are available in ProteoRE, a freely accessible Galaxy-based instance ${ }^{9}$ dedicated to biomedical research ${ }^{10,11}$. Likewise, results and computational outputs have been shared for re-use by experts from the community of reproductive biologists. 


\section{MATERIALS AND METHODS}

\section{Public resources used: content and release information}

Expression profiles for transcripts and proteins in human male tissues (testis, epididymis, ductus deferens, seminal vesicle and prostate) based on RNA sequencing analysis and immunohistochemistry, respectively, were downloaded from Human Protein Atlas (HPA) (https://www.proteinatlas.org/humanproteome/tissue; version 19.2 and Ensembl version 92.38). Lists of functionally unannotated and missing protein entries were retrieved from neXtProt using SPARQL queries NXQ_000022 and NXQ_00204 respectively (February 2020). Human protein complex map files (hu.MAP 2.0) were downloaded from http://hu.proteincomplexes.org/download. Literature survey was performed using Pubmed, GoogleScholar and the GenCLiP3 web application (http://ci.smu.edu.cn/genclip3/analysis.php).

\section{Bioinformatics analyses}

The tools implemented and used in this study are part of the freely accessible ProteoRE platform: http://www.proteore.org. Specifically, data retrieval, mapping identifiers from Ensembl to neXtProt, results manipulation and Venn diagram were performed using the following tools of ProteoRE: "Data manipulation and visualization" section: "ID Converter (Human, Mouse, Rat)", "Filter by keywords and/or numerical value", "Venn diagram [JVenn]"; "Get Features/Annotation" section: “Add expression data (RNAseq or Immuno-assays) [Human Protein Atlas]", "Add protein features [neXtProt]"; "Pathways analysis" section: "Build Protein interaction network [BioGRID, BioPlex, HuMAP]". For ease of use, a detailed user documentation is provided for each tool at the bottom of the central panel of the Galaxy workflow. This documentation describes what the tool does, the input it requires, parameters to be tuned, and the output produced and lists data sources, along with their release date when applicable. 


\section{Mapping from Ensembl to neXtProt}

Each ENSG identifier was converted into a neXtProt identifier using mapping tables from neXtProt (ftp://ftp.nextprot.org/pub/current release/mapping/ - March 2020). 126 HPA entries with ENSG identifiers that do not map to any neXtProt ID were removed from the study. Most of these unmapped ENSG identifiers correspond to "overlapping locus" in which exon(s) overlap exon(s) of a readthrough transcript or a transcript belonging to another locus. Such locus are not represented in UniProtKB/Swiss-Prot or neXtProt because their biological relevance at protein level is unsure. In addition, we manually verified and corrected cases where neXtProt ID map to several ENSG ID (e.g. NX_A1L429 <-> ENSG00000237671; ENSG00000227488; ENSG00000216649) and reciprocally (e.g. ENSG00000212710 <=> NX_Q96RT6; NX_Q9HC47).

\section{Protein complex map visualization}

The tabular files with network and nodes attributes were generated by the "Build Protein interaction network [BioGRID, BioPlex, HuMAP]" tool of ProteoRE by selecting hu.MAP as resource (see above). These two files were uploaded in Cytoscape software (Version 3.7.2) (http://www.cytoscape.org) to visualize the protein complex map including the functionally unannotated proteins (uPE1). In this network, nodes represent proteins (unknown and known function) with their expression level in testis and their first interactors, whereas edges between nodes represent protein-protein physical interaction along with their interaction score according to hu.MAP. A visual style (e.g., node shape, continuous mapping color, edge width) was mapped to node and edge attributes, highlighting uPE1 in their cellular and molecular context (see Figure 4 and 5 legends).

\section{History, datasets and availability of analyses}

Datasets (testis "tissue_category_rna_testis_Tissue.tsv" ; epididymis “tissue_category_rna_epididymis_Tissue.tsv_ ; ductus deferens 
"tissue_category_rna_ductus.tsv"; seminal vesicle "tissue_category_rna_seminal” ; prostate “tissue_category_rna_prostate_Tissue"), used and results (network and node attributes files (.tsv) and network (.cys format)) produced in this study, have all been shared and made available at http://www.proteore.org (via shared data menu: "Data libraries" -> "Human male reproduction uPE1 datasets") (available after free registration). History can also be accessed and imported the following link: http://www.proteore.org/u/yvdb/h/buildingunknownproteomemaletissue2020 (name: “Building_UnknownProteome_MaleTissue_2020”).

\section{RESULTS AND DISCUSSION}

Overall workflow

The overall workflow for establishing the functionally unannotated proteome of human male tissue, and to build functional hypotheses for UPE1 proteins discussed herein, is illustrated in Figure 1 and described in the Material and Methods, with full details about results availability. Briefly, the core proteome of the human male reproductive system was built using the Human Protein Atlas (HPA) database by selecting genes/proteins flagged as "elevated" in at least one of the five human male tissues available. These tissues are: testis, epididymis, ductus deferens, seminal vesicle and prostate (Figure 2). This set of 2714 entries was compared to the unknown proteome and the latest release of the missing proteome (February 2020, SPARQL query NXQ_00204) enabling to select 412 protein entries which are PE1 with no function annotation (Figure 3). Then we performed a survey literature and identified five uPE1 (TEX33, CCDC38, CFAP70, CFAP58, C3orf62 and ANKDR55) for which a functional role was recently reported (Table 1). In parallel, this set of 412 uPE1 was placed in their cellular and molecular context by mapping them to the human protein complex map (hu.MAP), a public resource integrating over 9000 protein interaction datasets ${ }^{12}$ (Figure 4). Mapping co-complex membership of uPE1 proteins revealed five protein complexes for which we have developed functional hypotheses 
by considering additional information such as co-expression and co-localization (from HPA and neXtProt), and experimental evidence from literature mining. This strategy enabled us to propose a potential functional role for five uPE1 (CCDC112, TEX9, CCDC183, C3orf62 and MAGEB4) (Figure 5) out of seven (Table 3), in link with human male reproduction.

\section{Building a core proteome of the human male reproductive system}

The core proteome of the male reproductive system was built using the Human Protein Atlas (HPA) database $\mathrm{e}^{5,13}$. To the best of our knowledge, this database is one of the most exhaustive resources on human protein localization and expression. Its most recent version includes five tissues that are parts of the male reproductive system: testis, epididymis, ductus deferens, seminal vesicle and prostate. We restricted our study to genes/proteins flagged as "elevated" according to the tissue specificity category defined by HPA (i.e., belonging to the HPA categories "tissue enriched", "group enriched" and "tissue enhanced") in male tissues 5 , thus possibly related to male reproductive physiology. Tissue specificity category is defined based on the total set of all normalized expression (NX) in 37 tissues, 18 blood cell types or 64 cell lines and using a cutoff value of $1 \mathrm{NX}$ as a limit for detection across all tissues or cell types. According to HPA definition, "tissue enriched" corresponds to a NX level in a particular tissue/region/cell type at least four times any other tissue/region/cell type, "group enriched" to NX levels of a group (of 2-5 tissues or 2-10 cell types) at least four times any other tissue/region/cell type and "tissue enhanced" to NX levels of a group (of 1-5 tissues or 1-10 cell types) at least four times the mean of other tissue/region/cell types. As expected, the number of genes showing an elevated expression in testis is far higher compared to the four other male tissues (Figure 2, lower part), while the number of genes with elevated expression in two or three male tissues is rather low: 71 genes are elevated both in testis and epididymis and 50 genes are elevated in both ductus deferens and seminal vesicle (Figure 2, upper part), including semenogelins 1 (SEMG1) and 2 (SEMG2), which are predominant in semen. These two 
proteins have antibacterial activity and are involved in sperm motility ${ }^{14}$. Seventeen genes are elevated in ductus deferens, seminal vesicle and epididymis (Figure 2, upper part). Very few genes have elevated expression in other combinations of three tissues. One of them is KIAA1210, a uPE1 protein that is elevated in testis, epididymis and seminal vesicle and reported as enhanced in cancer prostate in HPA. The mouse ortholog of KIAA1210 has been suggested to be an essential cell junction protein interacting with topoisomerase TOP2B to regulate the dynamic change of chromatin structures during spermiogenesis ${ }^{15}$. Spermiogenesis is the final postmeiotic phase of spermatogenesis (for a review see ${ }^{16}$ ). We also noticed the presence of MSMB, a uPE1 protein whose expression is restricted to the prostate at a very high level (Table S1, normalized expression value 437). The MSMB gene encodes betamicroseminoprotein (MSP), a member of the immunoglobulin binding factor family synthesized by epithelial cells of the prostate and secreted into seminal plasma. MSP has been proposed as a serum marker for early detection of high grade prostate cancer ${ }^{17}$.

\section{Establishing the functionally unannotated human male tissue proteome}

These five male tissue datasets were then concatenated, and duplicated entries sorted out resulting in 2,883 ENSG entries, among which 2,757 were successfully mapped to 2,714 neXtProt entries constituting "the human male proteome". Out of these 2714 neXtProt entries, 25 are flagged as PE5 and probably correspond to non-coding elements, whereas 2134 were validated at protein level (PE1). 555 are only validated at transcript level (PE2) and await confident detection at protein level. Specific mass spectrometry-based workflows aiming at identifying these proteins in testis or sperm have been conducted by several HPP teams ${ }^{6,7,18-20}$. As the neXtProt list also contains functionally unannotated proteins with no experimental evidence at the protein level (i.e. missing proteins), we restricted our inventory to the functionally unannotated proteins assigned with a PE1 status indicating that there is experimental evidence for the existence of at least one proteoform in the entry. The comparison 
between the human male proteome, the unknown proteome and the latest release of the missing proteome (February 2020, SPARQL query NXQ_00204) showed there are currently 583 neXtProt functionally unannotated entries having elevated expression level in the Human male tissue (Figure 3). Out of these, 412 are PE1 validated proteins with no function annotated and thus constitute the current uncharacterized human male tissue proteome. Experimental information, annotations and features associated with these 412 proteins matching to 428 Ensembl entries were retrieved from HPA and neXtProt and gathered in Table S1. A quarter of the 428 Ensembl entries (101) have detectable mRNA expression only in testis (Table S1, in blue), and 165 others are mainly expressed in testis but also detectable in other tissues (Table $\mathrm{S} 1$, in light blue). For these entries, we suggest a role in spermatogenesis or testis development. For 14 Ensembl entries, expression was restricted to male tissues but not only to testis, suggesting a role in male reproduction that might be different from spermatogenesis or testis development (Table S1, in green). For 26 Ensembl entries, high expression levels were found in both testis and Fallopian tubes. As Fallopian tubes are ciliated organs, high levels in both testis and Fallopian tube may indicate a role in cilia biogenesis or function (Table S1, in yellow). The remaining proteins are expressed in male tissues but also in other tissues such as the brain, blood or skin, suggesting that they can perform functions not specific to the male reproductive system.

\section{Updating the functionally unannotated male tissue proteome}

The set of 412 uPE1 was first compared to the consolidated list of uncharacterized proteins published by Duek et al., in their seminal article ${ }^{21}$. We noticed eight proteins for which a functional hypothesis has been proposed and extensively discussed by the authors. Six may be involved in ciliogenesis (CASC1, CCDC33, CCDC172, CFAP45, ODF3L1, ODF3L2), one in late spermatogenesis (TEX44), and one in the gut-brain-microbiota axis (NXPE2). Interestingly, in the testis NXPE2 is moderately and uniformly expressed in the germ cell 
lineage, whereas a strong expression was observed in the head of the epididymis with typical secretion patterns in the pseudostratified columnar epithelium. There, the so-called principal cells possess microvilli that serve to resorb the fluid originating from the testicular secretion ${ }^{22}$. Fluid resorption is a function somewhat similar to that of cells in the salivary gland acini that also display a strong NXPE2 immunoreactivity. We also noticed the presence of PNMA6E, a protein only expressed in the germ cell lineage up to meiosis in testis, and to a lower extent in the ovary and Fallopian tubes, for which a role in gametogenesis was recently proposed ${ }^{23}$. We performed a survey of the literature published on these 412 uPE1 proteins using various search engines and could find a publication reporting the location of TEX33 in the mouse male germ cell lineage ${ }^{24}$. We also found publications reporting functional roles for $\mathrm{CCDC} 38^{25}, \mathrm{CFAP} 70^{26}$, $\mathrm{CFAP}^{27} 8^{27}$ and $\mathrm{C} 3$ orf62 28 (further discussed in this study) in spermatogenesis, and for ANKDR45 in cell proliferation ${ }^{29}$ (Table 1). The five latter proteins should no longer be considered as "uPE1" according to neXtProt criteria. The function of CFAP70 has just been annotated in UniProt and neXtProt (Release 2020-07-17). Update requests were sent to the UniProt team for the four other ones.

\section{Putting the male tissue UPE1 proteins in their cellular and molecular context}

The vast majority of cellular functions are carried out by molecular machines made up of noncovalent protein-protein interactions (PPIs) and called protein complexes. Putting uPE1 proteins in their molecular context as well as considering their cellular localization can be a valuable approach for predicting their functional role. In line with this idea, Drew et al., ${ }^{12}$ constructed a global human protein complex map (hu.MAP) by re-analyzing over 9,000 largescale human protein complex mass spectrometry experimental datasets obtained on cell lines. They showed that integrating these datasets provided substantial improvement on discriminating true and false protein interactions, and allowed to highlight both known and novel complexes relevant to ciliopathies. For instance, the global map predicted an interaction 
between the uPE1 ANKRD55 (Ankyrin repeat domain-containing protein 55) and the IFT-B complex, that is one of the two sub-complexes of the IFT (Intraflagellar Transport) system, which link cargos to microtubule motors for transport along ciliary axonemes ${ }^{30}$. This interaction was validated in vivo by confocal imaging and genetic perturbation ${ }^{12}$. Inspired by this approach, we looked for publicly available interactomics data on the 412 uPE1 proteins with an elevated expression in the human male tissues. As we were unable to find publicly available data from experiments performed in human testis (or sperm) samples, we constructed a network using the hu.MAP resource to map co-complex membership of uPE1 proteins with an elevated expression in the human male tissue, and to explore their potential for revealing consistent functional relationships within protein complexes. Whereas $22 \%$ of all the uPE1 proteins $(286 / 1254)$ have data in Hu.MAP, only $10 \%$ of the uncharacterized proteins that are enriched in male tissues $(41 / 412)$ do so. This indicates that a number of the $412 \mathrm{uPE} 1$ proteins enriched in male tissues may have specific interactors in male tissues that cannot be studied in cell lines. The 41 uncharacterized proteins that are enriched in male tissues and have data in hu.MAP mapped onto 37 protein complexes. We hypothesized that most of these interactions would be conserved in male tissues. Using graphical functionalities of Cytoscape, a global view of these complexes was built highlighting uPE1, their expression level, their interacting partners and the predicted interaction score (Figure 4).

\section{Building functional hypothesis by combining predicted complexes, specialized database annotations and literature survey}

We elaborated functional hypothesis on some uPE1 by using graphical properties and node attributes of this protein complex network (Figure 4). Since more and more proteins are found to have different roles depending on their cellular context ${ }^{31}$, it is important to check that the interactions highlighted in the hu.MAP network can have functional relevance in male tissues. Therefore, we made sure to select protein pairs that are found in the same cellular compartments 
and have shared expression in male tissues. Protein-protein interaction scores (edge thickness), shared expression level in male tissue (node color gradient) and protein features such as subcellular co-localization (nodes attributes) were used to select the most likely protein complexes. According to Drew et al., an interaction score greater than 0.27 is considered as of very high confidence ${ }^{12}$. Using this score threshold and visual properties, five protein complexes were selected (Figure 5). Annotation and experimental data associated with each protein from these five complexes are provided in Table 2 (detailed information in Table S2).

ANKRD55 has an elevated expression in testis and is one of the $412 \mathrm{uPE} 1$ proteins from our set. Unsurprisingly, one of the five selected complexes is the previously reported complex formed by ANKRD55 and three components of the IFT-B complex (IFT52, TTC30A and TTC30B) $)^{32-34}$ (Figure 5A).

With the aim of unraveling possible physiological roles for uPE1s in male germ cells and sperm maturation, each protein component of the four other selected complexes was investigated further by mining the literature. We first focused on two uPE1 members of the CCDC (coiledcoil domain containing) protein superfamily ${ }^{35}$, CCDC112 and CCDC183. Dimeric coiled coils are structural motifs known to mediate protein-protein interaction driving dynamic assembly of protein complexes ${ }^{36}$, and some coiled-coil domain containing proteins have been shown to be involved in the biology of cilia and flagella (e.g., CCDC114, CCDC169, CCDC34, CCDC40) ${ }^{37}$. Secondly, we investigated C3orf62, recently studied using knockout $(\mathrm{KO})$ male mice ${ }^{28}$ for a possible role in chromatin remodeling via an interaction with an histone acetyltransferase. At last, we discussed a complex composed of several cancer/testis (CT) antigens, a family of proteins only expressed in germ cells and aberrantly expressed in various human cancers.

\section{CCDC112 and TEX9 are centriolar satellite proteins regulating ciliogenesis}

CCDC112 was confidently predicted to interact with TEX9, another uPE1 protein (interaction score $=0.95$ ), and less confidently (interaction score $=$ confidence score 0.15 ) with NOL4 and 
NOL4L, two nucleolar-localized proteins of unknown function (Figure 5B). According to the interaction score threshold considered in hu.MAP, NOL4 and NOL4L are likely false positives. CCDC112 and TEX9 are not only expressed in the five male tissues (at mRNA level) but also in all, or many other examined tissues examined by HPA respectively (Table S2). These two proteins were reported to interact in an independent study investigating the dynamic changes in the centrosome-cilium protein interaction landscape during ciliogenesis ${ }^{38}$. They were shown to co-localize in centriolar satellites, which are membraneless granules that localize and move around centrosomes and cilia, and are key regulators of cilia, flagella and centrosome biogenesis $^{39-41}$. During the maturation of spermatids, centrioles are important to form the sperm flagellum and for sperm movement. Failure to properly regulate centrosome function could be associated with male infertility ${ }^{42,43}$. Considering that satellite proteins have been shown to regulate ciliogenesis ${ }^{44,45}$ and centriole assembly ${ }^{40,46}$, refining the role of CCDC112 and TEX9 in the assembly, maintenance and remodeling of the centrosome/cilium complex, could be particularly informative with respect to male infertility.

\section{CCDC183 as essential in sperm development and maturation?}

According to HPA, CCDC183 is only expressed in testis (Table S2). The protein expression pattern of immunohistochemistry (IHC) data from HPA for CCDC183 is assigned with an "uncertain" reliability score in HPA (Table 2), but single-cell RNA sequencing data reveals that CCDC183 is upregulated during the transition from the secondary spermatocytes to round spermatids, and downregulated during late spermiogenesis ${ }^{47}$. A proteomic analysis (SWATHMS) of good- vs. poor-quality human sperm in a human cohort showed that CCDC183 is highly abundant in the good-quality spermatozoa ${ }^{48}$. Of note is that according to the World Health Organization, and among other features, good-quality sperm display at least $80 \%$ forward progressive motility upon Percoll gradient density centrifugation. In this study poor-quality sperm fractions are asthenozoospermic with $<60 \%$ forward progressive motility and correlated 
with lower levels of CCDC18348. We thus investigated for clues supporting a role of CCDC183 in sperm motility. The predicted module containing CCDC183 revealed seven protein-protein interactions, each having a high interaction score (ranging from 0.64 to 0.96) (Figure 5C). According to HPA, these seven interactors are expressed in all examined tissues including testis, and IHC data for FOXP1, RABEP1, RUNDC1, TEDC1 and TMF1 proteins show an immunostaining ranging from moderate to strong in seminiferous tubules. The interaction between CCDC183 and FOXP1, a transcriptional repressor, could be relevant for the acquisition of motility by sperm cells, as FOXP1 was suggested to play a role in the regulation of ciliogenesis ${ }^{49}$. Likewise, TEDC1 has been shown to be required for centriole stability ${ }^{50}$. TMF1 (TATA element modulatory factor, also known as androgen receptor-associated protein of $160 \mathrm{kDa}$ (ARA160)) is not known to be involved in flagella formation but plays a role in sperm development. Indeed its murine ortholog was characterized as a Golgi-associated protein essential for acrosome formation during sperm development ${ }^{51}$; it was also observed in post meiotic germ cells (i.e., early/round spermatids) in human and found to be mainly localized in the Golgi apparatus in cell lines. The early steps of spermiogenesis are characterized by reorientation of the Golgi towards the cell nucleus, and tethering of trans-Golgi-derived vesicles onto the acroplaxome to initiate acrosome formation in early/round spermatids ${ }^{52,53}$. In Tmf mutant mice spermatids, the Golgi apparatus has abnormal orientation and the pro-acrosomal vesicles lose their guidance towards the nucleus ${ }^{54}$. These results suggest the involvement of this protein in the spatial re-orientation of the Golgi apparatus during the so-called Golgi-phase during which the organelle produces and releases lytic enzymes that will accumulate inside the forming acrosome in maturing spermatids. Furthermore, RABEP1 and RABGEF1, both localized in early endosomes, play a role in endocytic trafficking between endosome and transGolgi networks ${ }^{55}$. These proteins might also be involved in acrosome biogenesis. Investigating the functional links that potentially exist between CCDC183, FOXP1, TEDC1, TMF1, 
RABEP1 and RABGEF1, might be of high interest, particularly with respect to its potential role during the biogenesis of flagellum and acrosome in haploid male germ cells.

\section{C3orf62 may be involved in spermatogenesis by modulating the chromatin remodeling}

Chromatin remodeling is an essential process for normal sperm development ${ }^{56,57}$ and fertilization $^{58,59}$. During spermiogenesis, most of the germ cell cytoplasm, intracellular organelles and presumably a number of cytoplasmic proteins, are eliminated through residual bodies. Concomitantly, the chromatin undergoes extensive remodeling as most of the histones are replaced by highly basic protamines ${ }^{60}$. As a result, transcriptional activity is greatly repressed due to the packaging of sperm chromatins. Chromatin remodeling involves a dynamic interchange between open (transcriptionally active) and closed (transcriptionally repressed or silenced) chromatin structures, and is controlled by enzymatic modification of the DNA and/or histone proteins, such as DNA methylation and histone acetylation, respectively. With this respect, the interaction of C3orf62 with EP300, a histone acetyltransferase that regulates transcription via chromatin remodeling ${ }^{61}$ (confidence score $\sim 0.8$ ) caught our attention (Figure 5D). C3orf62 mRNA is expressed in testis and in blood while EP300 mRNA is expressed in all HPA tissues (Table 2, Table S2). There is no data available for C3orf62 protein expression in tissues, but this protein was detected in nuclear speckles in human cancer cell lines (A-431, U-2 OS and U-251 MG). Nuclear speckles are located in the interchromatin regions of the nucleoplasm of mammalian cells ${ }^{62}$. They are dynamic structures, and their constituents exchange continuously with the nucleoplasm and other nuclear locations ${ }^{63}$. As EP300 was reported to be located in the nucleoplasm, deeper experimental investigations are required to determine if EP300 and C3orf62 may co-localize either in the nucleoplasm or in speckles, and in which conditions. Our literature survey revealed a recent study ${ }^{28}$ about the role of the murine ortholog of C3orf62 highly expressed in spermatocytes. Using a 1700102P08Rik deficient mouse model generated by CRISPR-Cas9, the study showed that the disruption of 
1700102P08Rik causes a germ cell maturation arrest at the spermatocyte stage, indicating that this gene is essential for spermatogenesis and that its dysfunction leads to male infertility ${ }^{28}$. The authors also found that C3orf62 mRNA is downregulated in infertile patients with a spermatocyte maturation arrest. Together, these experimental observations could support the hypothesis that C3orf62 interacts with EP300, by modulating its activity and consequently chromatin remodeling in haploid germ cells.

\section{The enigmatic case of the $M A G E-B$ protein family}

Cancer/testis antigens (CTA) are encoded by genes that are normally expressed only in the human germ cell lineage, but are also expressed in various tumor types. The aberrant expression of germline genes in cancers reflects the activation of the silenced gametogenic program in somatic cells, and suggests that this programmatic acquisition is one of the driving forces of tumorigenesis ${ }^{64}$. Here we focused on MAGE (melanoma-associated antigen) B, a CTA family composed of ten genes located on Xp21-p22 chromosome. The human complex map reveals that three MAGEB (i.e., B3, B4 and B6) proteins form an intricate network composed of eleven proteins with multiple interactions (Figure 3). When restricting this complex by selecting protein-protein interactions of high confidence (i.e., score $>0.3$ ), we obtained a smaller network composed of MAGEB3, MAGEB4, MAGEB6, MAGEA1 (another CTA encoded by a gene located on Xq28), and ROCK1 (Rho-associated protein kinase 1). MAGEA1 interacts with MAGEB3, B4 and B6, while MAGEB4 interacts with ROCK1 (Figure 5E). Gene expression of MAGEA1 and MAGEB6 are restricted to testis (detected in single), while MAGEB3 and MAGEB4 are both expressed in testis and epididymis, and ROCK1 is expressed in all tissues. Visual inspection of IHC data performed on human testis sections (HPA) confirmed MAGEA1, MAGEB3, MAGEB6 and ROCK1 to be expressed in germ cells at all stages of spermatogenesis, with higher expression levels in spermatogonia and meiotic spermatocytes. MAGEB4 is expressed at very low levels at all stages. MAGEA1 has been proposed to act as a 
potent transcriptional repressor and participate in the setting of specific gene expression patterns in spermatogenesis ${ }^{65}$. Interestingly, data from single-cell RNA sequencing analysis of human male germ cell transitions revealed that both MAGEA1 and MAGEB6 were expressed in early primary spermatocytes, with a similar differential expression pattern during spermatogenesis (i.e., up from differentiated spermatogonia to preleptotene spermatocytes stages and then down past meiosis $)^{47}$. No single-cell RNA sequencing is available for MAGEB3 and MAGEB4. In the developing mouse testis, the Mageb4 gene was shown to be highly expressed in proliferating gonocytes until they arrest at the G0/G1 phase and thus likely maintains gonocytes in a non-proliferative state. When Mage-b4 gene is down regulated in the adult testis, the germ cells are allowed to enter the first meiotic division ${ }^{66}$.

Rho kinases ROCK1 and ROCK2 are effectors of the small GTPase Rho. ROCKs are important cytosolic nodes whose activation leads to numerous downstream events such as actin polymerization, focal adhesion, and stress fiber formation (for a review see ${ }^{67}$ ). It has been suggested that, in the testis, ROCKs and Rho GTPase play a role in the assembly of Sertoligerm cell actin-based adherens junction $(\mathrm{AJ})^{68}$. However, no experimental data could be found on the possible interaction between MAGEB4 and ROCK1. One may hypothesize that both proteins could be functionally related during the transformation of primordial germ cells (PGC) into gonocytes and their further maintenance in a non-proliferative state. The small MAGEB3, MAGEB4, MAGEB6, MAGEA1 and ROCK1 network highlighted in this study could thus be of major importance to explain failed gonocytes differentiation into carcinoma in situ and/or germ cell maturation arrests at later stages of spermatogenesis.

\section{CONCLUSIONS}

This study is a first attempt to establish an inventory of 412 proteins expressed in the human male reproductive system for which a functional role is still unknown (uPE1). Messenger RNA and protein expression are strictly regulated during spermatogenesis and the process involves a 
myriad of coordinated events (for review see ${ }^{4}$ ). As a consequence, the simple assessment of expression levels during spermatogenesis can be misleading in the absence of a more detailed knowledge on the regulation of isoforms and differences in the fates of products ${ }^{69}$, but also on interactions between proteins and their involvement into functional complexes. Assigning one or more biological functions to functionally unannotated proteins expressed in the human male reproductive system can help to discover potential biomarkers for spermatogenesis and male reproductive pathologies, among which are testicular cancers and infertilities.

How to prioritize these proteins and upon which criteria for a wet biologist is a non-trivial question. Most testicular proteins with unknown function are expressed in the germ cell lineage, and it may be difficult for scientists other than those with extensive experience on spermatogenesis to access the relevant biological samples for further characterization of uPE1. Importantly, access to human testes is limited and requires ethical authorizations. Furthermore, reproductive biologists regret the impossibility of using some of the classic approaches of cell and molecular biology. As a matter of fact, quality immortalized germ cell lines do not really exist, especially because immortalization is not compatible with meiosis. For direct studies on the germ cell lineage, it is therefore mandatory to use freshly purified germ cells from human testis, taking into consideration that the more differentiated they are, the lower their survival rate upon isolation. Moreover transfection of meiotic and post meiotic germ cells is still challenging, if not impossible, making this approach unsuitable to study the function and regulation of genes or gene products. Regarding the $85 \%$ of proteins that have orthologs in rodents, a reasonable option is to use mouse KO models. The Mouse Genome Informatics (MGI) database ${ }^{70,71}$ is a reliable resource for narrowing down candidate genes, the inactivation of which affects male fertility. As of June 2020, entries in the MGI mammalian phenotype browser such as "male infertility", "reduced male fertility" and "abnormal sperm" corresponded respectively to 1280,406 and 949 phenotypes. Of course, also of potential interest will be any 
protein identified in a protein-protein interaction experiment for which the referenced partner in the MGI knowledgebase would match with an infertility phenotype. Fortunately, we can rely on the International Mouse Phenotyping Consortium (IMPC; https://www.mousephenotype.org), a global effort to identify the function of every proteincoding gene in the mouse genome ${ }^{72}$ to order animals at reasonable cost. At best, mouse strains generated by the IMPC can be obtained as a conditional ready allele that allows tissue restricted knockouts via either the Cre-Lox or FLP-FRT recombination systems. In order to perform a thorough analysis of a reproductive phenotype, a large colony must be obtained so as to get about 30-40 knockout males reaching adulthood. Parameters to be measured will be fertility in terms of sexual behavior and mating outcome, LH, FSH and testosterone concentrations in serum, reproductive organ weights and anatomy, testicular quantitative histology, sperm reserves, and if sperm is produced, a complete evaluation of sperm quantitative and qualitative traits (concentration, morphology, mobility...). A complete integration of the data will conclude whether the candidate gene is an essential player in the control of male reproductive function in the mouse. However, the cost and the timeline of such an approach have significant limitations that only allow a handful of candidate genes/proteins to be functionally studied by a single laboratory. As soon as testicular germ cell proteins focus attention, uPE1 which are of most interest are those linked to centrosomes, cilia and acrosome development that are likely to be involved in the formation and functioning of the sperm flagella, the acrosome biogenesis, or the acrosome reaction. These uPE1 proteins potentially represent quality traits and could help in delineating sperm quality apart from semen analysis, especially in the case of idiopathic male infertility. Novel information on ciliary or acrosomal proteins will help understand sperm biology and idiopathic infertilities, ultimately offering perspectives on the counselling of male patients about their fertility status and about possible clinical treatments required for conceiving. 
This is typically illustrated by the case of C2orf62. This protein is a former uPE1 protein produced in large amounts in the testes of zebrafish, rat and human that was shown to regulate actin polymerization and ciliogenesis and proposed to be involved in processes occurring before or during the formation of mature spermatozoa ${ }^{73}$. Recently a recessive mutation of C2orf62 (CATIP) was described in humans that may contribute to asthenozoospermia through its involvement in actin polymerisation and on the actin cytoskeleton in sperm $^{74}$, confirming the study published six years before.

Here we implemented a knowledge-driven approach assisted by computing tools that allowed us to propose functional hypotheses related to male reproduction physiology (ciliogenesis, spermatogenesis and sperm maturation) for five uPE1 (Table 3). Based on the above data, CCDC112, TEX9, C3orf62 and CCDC183 are supposed to be involved in the biology of mature germ cells. Their further study using knockout mice models of ortholog genes is relevant. Through a registered account, the IMPC website offers the possibility to indicate interest in a gene and get regular updates on its status (e.g., mouse production, phenotyping in process, phenotype data available). Interestingly, for all four candidates embryonic stem (ES) cells have already been produced by IMPC consortium partners. When mice are produced, phenotyping is organized into pipelines, which assess the mouse biology at different life stages from embryo to aged adults. A broad range of phenotyping tests are carried out among which that of the reproductive system. However, fertility phenotyping is gross since it is understandable that a consortium like IMPC cannot go into an in-depth evaluation of a testicular phenotype, as reproductive biologists would do. The following step is thus to order the mice and develop a colony to produce enough $\mathrm{KO}$ males in house to evaluate the role of these four genes into the biology of germ cells. The role of the MAGEB3, MAGEB4, MAGEB6, MAGEA1 and ROCK1 network in gonocytes differentiation could be advantageously studied using organotypic culture 
of mouse fetal gonads ${ }^{75}$, a model successively developed to get new insights into fetal testis development.

The functional characterization of human proteins could be accelerated by a better integration of existing knowledge resources and by initiating large collaborative projects involving specialists of different biology fields. To this end, bioinformatics coupled with biocuration is more than ever required to bridge annotation gaps and we hope this activity will receive more attention and support from the community. As we believe that this effort must be continued collectively, all results presented herein have been shared via ProteoRE for researchers who wish to reuse them to guide further experimentation about the possible function of these proteins highly enriched in the human male reproductive system. 


\section{TABLES:}

Table 1: List of uPE1 entries with elevated expression in human male tissues for which localization and/or functional characterization papers were found. (Chr.: Human chromosome number).

\begin{tabular}{|c|c|c|c|c|c|c|c|}
\hline Gene & NextprotID & $\begin{array}{l}\text { Year of } \\
\text { publication }\end{array}$ & Literature & Main conclusion & Functional role & Chr. & RNA tissue specific $\mathbf{N X}$ \\
\hline ANKRD55 & NX_Q5TZF3 & 2019 & PMID: 31208154 & $\begin{array}{l}\text { "Ankrd45 is required for cell } \\
\text { proliferation in both zebrafish embryos } \\
\text { and mammalian cells." }\end{array}$ & Cell proliferation & 1 & $\begin{array}{l}\text { brain: } 14.6 \text {;fallopian tube: } \\
\text { 24.8;parathyroid gland: } 16.8 \text {;pituitary } \\
\text { gland: } 7.9 \text {;testis: } 20.8\end{array}$ \\
\hline CCDC38 & NX_Q502W7 & 2016 & PMID: 27278724 & $\begin{array}{l}\text { "Ccdc38 is mainly localized in the } \\
\text { nuclei of spermatogonia and } \\
\text { spermatocytes of the mice seminiferous } \\
\text { tubules and interacted with } \\
\text { ubiquitinated histone H2A in mouse } \\
\text { testis." }\end{array}$ & Spermatogenesis & 12 & testis: 37.0 \\
\hline $\begin{array}{l}\text { CFAP58 } \\
\text { (CCDC147) }\end{array}$ & NX_Q5T655 & 2020 & PMID: 31904090 & $\begin{array}{l}\text { "Cfap58 is a testis-enrichment protein } \\
\text { that exhibits similar localization to } \\
\text { Odf } 2 / \text { Cenexin proteins and is required } \\
\text { for the elongation of the primary cilium } \\
\text { and sperm midpiece via modulation of } \\
\text { the Notch signaling pathway." }\end{array}$ & Cilia/Flagella elongation & 10 & fallopian tube: 10.9 ;testis: 17.5 \\
\hline CFAP70 & NX_Q5T0N1 & 2019 & PMID: 31621862 & $\begin{array}{l}\text { "Loss of CFAP70 function causes } \\
\text { MMAF (multiple morphological } \\
\text { abnormalities of the sperm flagella) and } \\
\text { that ODA-related proteins may be } \\
\text { crucial for the assembly and/or stability } \\
\text { of the flagellum axoneme in addition to } \\
\text { its motility." }\end{array}$ & Flagellum Assembly & 10 & pituitary gland: 27.2 ; testis: 22.3 \\
\hline C3orf62 & NX_Q6ZUJ4 & 2020 & PMID: 31930642 & $\begin{array}{l}\text { "We report that the testis-specific gene } \\
1700102 \mathrm{P} 08 \mathrm{Rik} \text { is highly expressed in } \\
\text { spermatocytes... we show that the } \\
\text { disruption of } 1700102 \mathrm{P} 08 \text { Rik causes } \\
\text { male infertility as a result of } \\
\text { spermatocyte arrest." }\end{array}$ & Spermatogenesis & 3 & blood: 25.0 ;testis: 76.9 \\
\hline TEX33 & NX_O43247 & 2018 & PMID: 30381129 & $\begin{array}{l}\text { "Tex } 33 \text { gene was expressed in } \\
\text { spermatids and sperms of adult mouse } \\
\text { testis. And Tex } 33 \text { was located on the } \\
\text { acrosome and flagellum of } \\
\text { spermatozoa." }\end{array}$ & Unknown & 22 & testis: 49.1 \\
\hline
\end{tabular}


Table 2: hu.MAP protein complexes containing uPE1. RNA tissue specificity: according to HPA data; Tissue RNA testis [NX]: normalized expression value in testis tissue according to HPA; Reliability score (IHC): score associated to immunohistochemistry data (detailed information in Table S2). *: uPE1 protein entries.

\begin{tabular}{|c|c|c|c|c|c|c|}
\hline \multicolumn{7}{|c|}{ ANKRD55 protein complex } \\
\hline $\begin{array}{c}\text { Gene Name } \\
\text { (official } \\
\text { symbol) }\end{array}$ & NextProt_ID & $\begin{array}{l}\text { RNA tissue } \\
\text { specificity }\end{array}$ & $\begin{array}{l}\text { Tissue } \\
\text { RNA } \\
\text { testis } \\
{[N X]}\end{array}$ & $\begin{array}{c}\text { Reliability } \\
\text { score } \\
\text { (IHC) }\end{array}$ & $\begin{array}{c}\text { Subcellular } \\
\text { location (HPA) }\end{array}$ & $\begin{array}{c}\text { Subcellular } \\
\text { location (neXtProt) }\end{array}$ \\
\hline ANKRD55* & NX_Q3KP44 & Group enriched & 16.7 & Uncertain & Nucleoplasm,Nuclear speckles,Cytosol & NA \\
\hline IFT27 & NX_Q9BW83 & Low tissue specificity & 20.1 & Uncertain & Nucleoplasm,Mitochondria & Nucleoplasm;Cytoplasm;Mitochondrion;Flagellum;Cilium \\
\hline IFT52 & NX_Q9Y366 & Low tissue specificity & 36.8 & Enhanced & Cytosol & Cytosol;Cilium \\
\hline TTC30A & NX_Q86WT1 & Tissue enhanced & 24.5 & Supported & Nucleoplasm,Centrosome & Cilium \\
\hline TTC30B & NX_Q8N4P2 & Low tissue specificity & 11.5 & Supported & Nucleoplasm,Centrosome & Cilium \\
\hline \multicolumn{7}{|c|}{ CCDC112 protein complex } \\
\hline $\begin{array}{c}\text { Gene Name } \\
\text { (official } \\
\text { symbol) }\end{array}$ & NextProt_ID & $\begin{array}{l}\text { RNA tissue } \\
\text { specificity }\end{array}$ & $\begin{array}{l}\text { Tissue } \\
\text { RNA } \\
\text { testis } \\
{[\mathrm{NX}]}\end{array}$ & $\begin{array}{c}\text { Reliability } \\
\text { score } \\
\text { (IHC) }\end{array}$ & $\begin{array}{c}\text { Subcellular } \\
\text { location (HPA) }\end{array}$ & $\begin{array}{c}\text { Subcellular } \\
\text { location (neXtProt) }\end{array}$ \\
\hline CCDC112* & NX_Q8NEF3 & Tissue enhanced & 40.4 & Uncertain & Nucleoplasm,Plasma membrane,Cytosol & Nucleoplasm;Cytosol;Cell membrane \\
\hline TEX9* & NX_Q8N6V9 & Tissue enhanced & 19.3 & Uncertain & Plasma membrane,Cytosol & Cytosol;Cell membrane \\
\hline NOL4 & NX_O94818 & Group enriched & 14.5 & NA & Nucleoplasm & Nucleolus;Nucleus \\
\hline NOL4L & NX_Q96MY1 & Low tissue specificity & 33.2 & Enhanced & Nucleoplasm & Nucleoplasm \\
\hline \multicolumn{7}{|c|}{ CCDC183 protein complex } \\
\hline $\begin{array}{c}\text { Gene Name } \\
\text { (official } \\
\text { symbol) }\end{array}$ & NextProt_ID & $\begin{array}{l}\text { RNA tissue } \\
\text { specificity }\end{array}$ & $\begin{array}{l}\text { Tissue } \\
\text { RNA } \\
\text { testis } \\
{[\mathrm{NX}]}\end{array}$ & $\begin{array}{c}\text { Reliability } \\
\text { score } \\
\text { (IHC) }\end{array}$ & $\begin{array}{c}\text { Subcellular } \\
\text { location (HPA) }\end{array}$ & $\begin{array}{c}\text { Subcellular } \\
\text { location (neXtProt) }\end{array}$ \\
\hline
\end{tabular}




\begin{tabular}{|c|c|c|c|c|c|c|}
\hline CCDC183* & NX_Q5T5S1 & Tissue enriched & 26.4 & Uncertain & NA & NA \\
\hline FOXP1 & NX_Q9H334 & Low tissue specificity & 11.7 & Supported & Nucleoplasm & Nucleoplasm;Nucleus \\
\hline RABEP1 & NX_Q15276 & Low tissue specificity & 11.8 & Supported & Vesicles & $\begin{array}{l}\text { Cytoplasmic vesicle;Cytoplasm;Recycling } \\
\text { endosome;Early endosome }\end{array}$ \\
\hline RABGEF1 & NX_Q9UJ41 & Low tissue specificity & 21.5 & NA & Nucleoli,Cytosol & $\begin{array}{l}\text { Cytosol;Cytoplasm;Recycling endosome; Nucleolus;Early } \\
\text { endosome }\end{array}$ \\
\hline RUNDC1 & NX_Q96C34 & Low tissue specificity & 11.9 & Uncertain & Nuclear speckles,Cytosol & Cytosol;Nucleus speckle \\
\hline TMF1 & NX_P82094 & Low tissue specificity & 20.9 & Approved & Golgi apparatus & $\begin{array}{l}\text { Nucleus;Golgi apparatus membrane;Golgi } \\
\text { apparatus;Cytoplasm }\end{array}$ \\
\hline C14orf80 & NX_Q86SX3 & Low tissue specificity & 9.1 & Uncertain & Nucleoplasm,Golgi apparatus,Cytosol & Cytosol;Nucleoplasm;Golgi apparatus \\
\hline CEBPA & NX_P49715 & Tissue enhanced & 1.2 & Approved & Nucleoplasm,Vesicles & Cytoplasmic vesicle;Nucleoplasm;Nucleolus;Nucleus \\
\hline \multicolumn{7}{|c|}{ C3orf62 protein complex } \\
\hline $\begin{array}{c}\text { Gene Name } \\
\text { (official } \\
\text { symbol) }\end{array}$ & NextProt_ID & $\begin{array}{l}\text { RNA tissue } \\
\text { specificity }\end{array}$ & $\begin{array}{l}\text { Tissue } \\
\text { RNA } \\
\text { testis } \\
{[N X]}\end{array}$ & $\begin{array}{c}\text { Reliability } \\
\text { score } \\
\text { (IHC) }\end{array}$ & $\begin{array}{c}\text { Subcellular } \\
\text { location (HPA) }\end{array}$ & $\begin{array}{c}\text { Subcellular } \\
\text { location (neXtProt) }\end{array}$ \\
\hline C3orf62* & NX_Q6ZUJ4 & Group enriched & 76.9 & NA & Nuclear speckles & Nucleus speckle \\
\hline EP300 & NX_Q09472 & Low tissue specificity & 20.6 & Supported & Nucleoplasm & Nucleoplasm;Cytoplasm;Nucleus;Chromosome \\
\hline \multicolumn{7}{|c|}{ MAGEB3/B4/B6 proteins complex } \\
\hline $\begin{array}{l}\text { Gene Name } \\
\text { (official } \\
\text { symbol) }\end{array}$ & NextProt_ID & $\begin{array}{l}\text { RNA tissue } \\
\text { specificity }\end{array}$ & $\begin{array}{l}\text { Tissue } \\
\text { RNA } \\
\text { testis } \\
{[N X]}\end{array}$ & $\begin{array}{c}\text { Reliability } \\
\text { score } \\
\text { (IHC) }\end{array}$ & $\begin{array}{c}\text { Subcellular } \\
\text { location (HPA) }\end{array}$ & $\begin{array}{c}\text { Subcellular } \\
\text { location (neXtProt) }\end{array}$ \\
\hline MAGEA1 & NX_P43355 & Tissue enriched & 13.5 & Enhanced & $\begin{array}{l}\text { Nuclear and cytoplasmic expression of } \\
\text { spermatogonia in seminiferous ducts in testis. }\end{array}$ & Cytosol;Cytoplasm;Nucleus \\
\hline MAGEB3* & NX_O15480 & Group enriched & 7.8 & Approved & Nuclear expression in testis and epididymis & NA \\
\hline MAGEB4* & NX_O15481 & Group enriched & 18.1 & Enhanced & Cytoplasmic expression in testis and epididymis & Cytoplasm \\
\hline
\end{tabular}




\begin{tabular}{|c|c|c|c|c|c|c|}
\hline MAGEB6* & NX_Q8N7X4 & Tissue enriched & 8.6 & Enhanced & $\begin{array}{l}\text { Cytoplasmic expression in testis, mainly in } \\
\text { spermatocytes }\end{array}$ & NA \\
\hline ROCK1 & NX_Q13464 & Low tissue specificity & 6.6 & Approved & NA & $\begin{array}{l}\text { Ruffle;Cytoplasm;Cell membrane;Centriole;Golgi } \\
\text { apparatus membrane;Bleb;Lamellipodium;Cytoskeleton }\end{array}$ \\
\hline
\end{tabular}


Table 3: Functional hypotheses on five uPE1 related to the male reproductive system. (Chr.: Human chromosome number; Reliability: score; RNA in each male tissue expressed in normalized expression value (NX) from HPA).

\begin{tabular}{|c|c|c|c|c|c|c|c|c|c|c|c|c|}
\hline $\begin{array}{l}\text { Gene } \\
\text { Name }\end{array}$ & NextprotID & Chr & $\begin{array}{l}\text { Supporting } \\
\text { literature } \\
\text { (PMID) }\end{array}$ & $\begin{array}{l}\text { Functional } \\
\text { hypothesis }\end{array}$ & Antibody & $\begin{array}{l}\text { Reliability } \\
\text { (IH) }\end{array}$ & $\begin{array}{l}\text { Subcellular location } \\
\text { (neXtProt) }\end{array}$ & $\begin{array}{c}\text { RNA } \\
\text { ductus } \\
\text { deferens }\end{array}$ & $\begin{array}{c}\text { RNA } \\
\text { epididymis }\end{array}$ & $\begin{array}{c}\text { RNA } \\
\text { prostate }\end{array}$ & $\begin{array}{c}\text { RNA } \\
\text { seminal } \\
\text { vesicle }\end{array}$ & $\begin{array}{l}\text { RNA } \\
\text { testis }\end{array}$ \\
\hline CCDC112 & NX_Q8NEF3 & 5 & 26638075 & $\begin{array}{l}\text { Regulation of } \\
\text { cilia and flagella } \\
\text { formation, } \\
\text { centriolar } \\
\text { satellite protein }\end{array}$ & $\begin{array}{l}\text { HPA045120, } \\
\text { HPA050621 }\end{array}$ & Uncertain & $\begin{array}{l}\text { Nucleoplasm;Cytosol;Cell } \\
\text { membrane }\end{array}$ & 4.3 & 7.3 & 7.7 & 8.6 & 40.4 \\
\hline TEX9 & NX_Q8N6V9 & 15 & 26638075 & $\begin{array}{l}\text { Regulation of } \\
\text { cilia and flagella } \\
\text { formation, } \\
\text { centriolar } \\
\text { satellite protein }\end{array}$ & HPA039415 & Uncertain & Cytosol;Cell membrane & 6.0 & 11.6 & 5.4 & 4.5 & 19.3 \\
\hline CCDC183 & NX_Q5T5S1 & 9 & 29228106 & $\begin{array}{l}\text { Spermiogenesis, } \\
\text { acrosome } \\
\text { formation, sperm } \\
\text { motility }\end{array}$ & HPA043812 & Uncertain & N.A. & 0.0 & 0.4 & 0.6 & 0.0 & 26.4 \\
\hline C3orf62 & NX_Q6ZUJ4 & 3 & $\underline{31930642}$ & $\begin{array}{l}\text { Chromatin } \\
\text { remodelling, } \\
\text { male germ cells } \\
\text { differentiation }\end{array}$ & HPA043328 & N.A. & Nucleus speckles & 4.4 & 4.9 & 4.1 & 2.2 & 76.9 \\
\hline MAGEB4 & NX_O15481 & $\mathrm{X}$ & $\underline{10706124}$ & $\begin{array}{l}\text { Male germ cells } \\
\text { differentiation }\end{array}$ & HPA030456 & Enhanced & Cytoplasm & 0.8 & 26.3 & 0.0 & 0.0 & 18.1 \\
\hline
\end{tabular}




\section{FIGURES:}

Figure 1: Flowchart illustrating the strategy used to establish the functionally unannotated human male tissue proteome and to build functional hypotheses.

Figure 2: Venn diagram showing the number of genes with an elevated expression in each human male tissue (testis, epididymis, ductus deferens, seminal vesicle and prostate) and the number of shared genes between each of them.

Figure 3. Venn diagram illustrating overlap between the set of proteins showing an elevated expression in the five human male tissue (testis, epididymis, ductus deferens, seminal vesicle and prostate), the set of unknown and missing protein entries from neXtProt (February 2020).

Figure 4. uPE1 with an elevated expression in the human male tissues mapped to the protein complex map hu.MAP. uPE1 were highlighted (hexagon nodes represent uPE1 proteins, while ellipse nodes represent their interactors ). Normalized expression (NX) values in testis are represented along a color gradient from white (no expression) to dark red (highest expression value). Gradient edge width is proportional to the hu.MAP interaction score (the thicker the edge, the higher the score).

Figure 5. A detailed view of uPE1 proteins interacting molecular assemblies. A. ANKRD55. B. CCDC183. C. CCDC112. D. C3orf62. E. MAGEB3, MAGEB4, MAGEB6 (graphical legends as in Figure 3).

\section{ASSOCIATED CONTENT}

\section{Supporting Information.}

Table S1: List of 412 uPE1 neXtprot entries with an elevated expression in the human male reproductive system (detailed information) (XLSX). Official gene name (gene), Ensembl identifier (Ensembl) was converted into a neXtProt identifier (NextprotID) using 
mapping tables from neXtProt (ftp://ftp.nextprot.org/pub/current_release/mapping/ - March 2020). Protein class(es) of the gene product (Protein class), RNA tissue specificity, RNA tissue distribution, consensus normalized expression (NX) value for each gene (RNA tissue specific NX), antibody product name (Antibody), reliabiliy score of each protein expression pattern measured by IHC (Reliability $(\mathrm{IH})$ ), normalized transcript abundance measured in each male tissue considered in this study (Tissue RNA - ductus deferens [NX] (column J), Tissue RNA epididymis [NX] (column K), Tissue RNA - prostate [NX] (column L), Tissue RNA - seminal vesicle $[\mathrm{NX}]$ (column M), Tissue RNA - testis $[\mathrm{NX}]$ (column N)) were retrieved from HPA. Protein sequence length (SeqLength), molecular weight MW), isoelectric point (IsoPoint), number of transmembrane domain (TMDomains), chromosome location (Chr), subcellular location (SubcellLocations (neXtProt Gold/Silver)), and disease (Diseases) information were retrieved from neXtProt.

Table S2: The five hu.MAP protein complexes containing uPE1 with an expression elevated in male tissues presented in this study (detailed information) (XLSX). Gene Name (official symbol), chromosome location (Chr), neXtProt identifier (NextprotID), protein name (Protein name), subcellular location (SubcellLocations (neXtProt)), entry name of the protein (Entry.name), (Protein.names), description of protein function (Function.[CC]), information about the protein quaternary structure and interaction(s) with other proteins or protein complexes (Subunit.structure.[CC]) were retrieved from neXtProt and Uniprot; RNA tissue specificity, RNA tissue distribution, consensus normalized expression (NX) value for each gene (RNA tissue specific NX), RNA cancer specificity, RNA cancer distribution, antibody product name (Antibody), reliabiliy score of each protein expression pattern measured by IHC (Reliability (IH)), normalized transcript abundance measured in each male tissue considered in this study (Tissue RNA - ductus deferens [NX], Tissue RNA - epididymis [NX], Tissue RNA 
- prostate [NX], Tissue RNA - seminal vesicle [NX], Tissue RNA - testis [NX]) were retrieved from HPA 


\title{
AUTHOR INFORMATION
}

\section{Corresponding Author}

*E-mail: yves.vandenbrouck@cea.fr

\section{ORCID}

Yves Vandenbrouck: 0000-0002-1292-373X

Charles Pineau: 0000-0002-7461-5433

Lydie Lane: 0000-0002-9818-3030

\section{Notes}

The authors declare no competing financial interest.

\section{Author Contributions}

The manuscript was written through contributions of all authors. All authors have given approval to the final version of the manuscript.

\section{ACKNOWLEDGEMENTS}

This work was partly supported by the "Investissement d'Avenir Infrastructures Nationales en Biologie et Santé” grants ANR-10-INBS-08 (Proteomics French Infrastructure - ProFI), ANR11-INBS-0013 (French Institute of Bioinformatics - IFB) (YV) and by the Swiss State Secretariat for Education, Research and Innovation SERI funding to the SIB Swiss Institute of Bioinformatics (LL). This work was also supported by grants from Biogenouest, IBiSA and the Conseil Régional de Bretagne (CP).

\begin{abstract}
ABBREVIATIONS
CTA, Cancer/testis antigens; HPA, Human Protein Atlas; HPP, Human Proteome Project, IHC, immunohistochemistry; KO, knockout; NP, neXtProt; NX, normalized expression; uPE1, unknown protein evidence 1.
\end{abstract}




\section{REFERENCES}

(1) Paik, Y.-K.; Lane, L.; Kawamura, T.; Chen, Y.-J.; Cho, J.-Y.; LaBaer, J.; Yoo, J. S.; Domont, G.; Corrales, F.; Omenn, G. S.; Archakov, A.; Encarnación-Guevara, S.; Lui, S.; Salekdeh, G. H.; Cho, J.-Y.; Kim, C.-Y.; Overall, C. M. Launching the C-HPP neXt-CP50 Pilot Project for Functional Characterization of Identified Proteins with No Known Function. J. Proteome Res. 2018, 17 (12), 4042-4050.

(2) Zahn-Zabal, M.; Michel, P.-A.; Gateau, A.; Nikitin, F.; Schaeffer, M.; Audot, E.; Gaudet, P.; Duek, P. D.; Teixeira, D.; Rech de Laval, V.; Samarasinghe, K.; Bairoch, A.; Lane, L. The NeXtProt Knowledgebase in 2020: Data, Tools and Usability Improvements. Nucleic Acids Res. 2019. https://doi.org/10.1093/nar/gkz995.

(3) Zahn-Zabal, M.; Lane, L. What Will NeXtProt Help Us Achieve in 2020 and Beyond? Expert Rev. Proteomics 2020, 17 (2), 95-98.

(4) Rolland, A. D.; Lavigne, R.; Dauly, C.; Calvel, P.; Kervarrec, C.; Freour, T.; Evrard, B.; Rioux-Leclercq, N.; Auger, J.; Pineau, C. Identification of Genital Tract Markers in the Human Seminal Plasma Using an Integrative Genomics Approach. Hum. Reprod. 2013, 28 (1), 199-209.

(5) Uhlén, M.; Fagerberg, L.; Hallström, B. M.; Lindskog, C.; Oksvold, P.; Mardinoglu, A.; Sivertsson, Å.; Kampf, C.; Sjöstedt, E.; Asplund, A.; Olsson, I.; Edlund, K.; Lundberg, E.; Navani, S.; Szigyarto, C. A.; Odeberg, J.; Djureinovic, D.; Takanen, J. O.; Hober, S.; Alm, T.; Edqvist, P.; Berling, H.; Tegel, H.; Mulder, J.; Rockberg, J.; Nilsson, P.; Schwenk, J. M.; Hamsten, M.; Feilitzen, K. Von; Forsberg, M.; Persson, L.; Johansson, F.; Zwahlen, M.; Heijne, G. Von; Nielsen, J.; Pontén, F. Tissue-Based Map of the Human Proteome. Science (80-. ). 2015, 347 (6220), 1260419-1260419.

(6) Vandenbrouck, Y.; Lane, L.; Carapito, C.; Duek, P.; Rondel, K.; Bruley, C.; Macron, C.; Gonzalez de Peredo, A.; Couté, Y.; Chaoui, K.; Com, E.; Gateau, A.; Hesse, A.-M.; Marcellin, M.; Méar, L.; Mouton-Barbosa, E.; Robin, T.; Burlet-Schiltz, O.; Cianferani, S.; Ferro, M.; Fréour, T.; Lindskog, C.; Garin, J.; Pineau, C. Looking for Missing Proteins in the Proteome of Human Spermatozoa: An Update. J. Proteome Res. 2016, 15 (11), 3998-4019.

(7) Carapito, C.; Duek, P.; Macron, C.; Seffals, M.; Rondel, K.; Delalande, F.; Lindskog, C.; Fréour, T.; Vandenbrouck, Y.; Lane, L.; Pineau, C. Validating Missing Proteins in Human Sperm Cells by Targeted Mass-Spectrometry- and Antibody-Based Methods. $J$. Proteome Res. 2017, 16 (12), 4340-4351.

(8) Wei, W.; Luo, W.; Wu, F.; Peng, X.; Zhang, Y.; Zhang, M.; Zhao, Y.; Su, N.; Qi, Y.; Chen, L.; Zhang, Y.; Wen, B.; He, F.; Xu, P. Deep Coverage Proteomics Identifies More Low-Abundance Missing Proteins in Human Testis Tissue with Q-Exactive HF Mass Spectrometer. J. Proteome Res. 2016, 15 (11), 3988-3997.

(9) Jalili, V.; Afgan, E.; Gu, Q.; Clements, D.; Blankenberg, D.; Goecks, J.; Taylor, J.; Nekrutenko, A. Corrigendum: The Galaxy Platform for Accessible, Reproducible and Collaborative Biomedical Analyses: 2020 Update. Nucleic Acids Res. 2020, 48 (14), 8205-8207.

(10) Nguyen, L.; Brun, V.; Combes, F.; Loux, V.; Vandenbrouck, Y. Designing an In Silico Strategy to Select Tissue-Leakage Biomarkers Using the Galaxy Framework. Methods Mol. Biol. 2019, 1959, 275-289. 
Vandenbrouck, Y.; Christiany, D.; Combes, F.; Loux, V.; Brun, V. Bioinformatics Tools and Workflow to Select Blood Biomarkers for Early Cancer Diagnosis: An Application to Pancreatic Cancer. Proteomics 2019, 19 (21-22), e1800489.

Drew, K.; Lee, C.; Huizar, R. L.; Tu, F.; Borgeson, B.; McWhite, C. D.; Ma, Y.; Wallingford, J. B.; Marcotte, E. M. Integration of over 9,000 Mass Spectrometry Experiments Builds a Global Map of Human Protein Complexes. Mol. Syst. Biol. 2017, $13(6), 932$.

(13) Thul, P. J.; Åkesson, L.; Wiking, M.; Mahdessian, D.; Geladaki, A.; Ait Blal, H.; Alm, T.; Asplund, A.; Björk, L.; Breckels, L. M.; Bäckström, A.; Danielsson, F.; Fagerberg, L.; Fall, J.; Gatto, L.; Gnann, C.; Hober, S.; Hjelmare, M.; Johansson, F.; Lee, S.; Lindskog, C.; Mulder, J.; Mulvey, C. M.; Nilsson, P.; Oksvold, P.; Rockberg, J.; Schutten, R.; Schwenk, J. M.; Sivertsson, Å.; Sjöstedt, E.; Skogs, M.; Stadler, C.; Sullivan, D. P.; Tegel, H.; Winsnes, C.; Zhang, C.; Zwahlen, M.; Mardinoglu, A.; Pontén, F.; von Feilitzen, K.; Lilley, K. S.; Uhlén, M.; Lundberg, E. A Subcellular Map of the Human Proteome. Science 2017, 356 (6340), eaal3321.

(14) de Lamirande, E. Semenogelin, the Main Protein of the Human Semen Coagulum, Regulates Sperm Function. Semin. Thromb. Hemost. 2007, 33 (1), 60-68.

(15) Iwamori, T.; Iwamori, N.; Matsumoto, M.; Ono, E.; Matzuk, M. M. Identification of KIAA1210 as a Novel X-Chromosome-Linked Protein That Localizes to the Acrosome and Associates with the Ectoplasmic Specialization in Testes. Biol. Reprod. 2017, 96 (2), 469-477.

(16) O'Donnell, L. Mechanisms of Spermiogenesis and Spermiation and How They Are Disturbed. Spermatogenesis 2014, 4 (2), e979623.

(17) Thomas, G.; Jacobs, K. B.; Yeager, M.; Kraft, P.; Wacholder, S.; Orr, N.; Yu, K.; Chatterjee, N.; Welch, R.; Hutchinson, A.; Crenshaw, A.; Cancel-Tassin, G.; Staats, B. J.; Wang, Z.; Gonzalez-Bosquet, J.; Fang, J.; Deng, X.; Berndt, S. I.; Calle, E. E.; Feigelson, H. S.; Thun, M. J.; Rodriguez, C.; Albanes, D.; Virtamo, J.; Weinstein, S.; Schumacher, F. R.; Giovannucci, E.; Willett, W. C.; Cussenot, O.; Valeri, A.; Andriole, G. L.; Crawford, E. D.; Tucker, M.; Gerhard, D. S.; Fraumeni, J. F.; Hoover, R.; Hayes, R. B.; Hunter, D. J.; Chanock, S. J. Multiple Loci Identified in a Genome-Wide Association Study of Prostate Cancer. Nat. Genet. 2008, 40 (3), 310-315.

(18) Jumeau, F.; Com, E.; Lane, L.; Duek, P.; Lagarrigue, M.; Lavigne, R.; Guillot, L.; Rondel, K.; Gateau, A.; Melaine, N.; Guével, B.; Sergeant, N.; Mitchell, V.; Pineau, C. Human Spermatozoa as a Model for Detecting Missing Proteins in the Context of the Chromosome-Centric Human Proteome Project. J. Proteome Res. 2015, 14 (9), 36063620 .

(19) Wei, W.; Luo, W.; Wu, F.; Peng, X.; Zhang, Y.; Zhang, M.; Zhao, Y.; Su, N.; Qi, Y.; Chen, L.; Zhang, Y.; Wen, B.; He, F.; Xu, P. Deep Coverage Proteomics Identifies More Low-Abundance Missing Proteins in Human Testis Tissue with Q-Exactive HF Mass Spectrometer. J. Proteome Res. 2016, 15 (11), 3988-3997.

(20) Zhang, Y.; Li, Q.; Wu, F.; Zhou, R.; Qi, Y.; Su, N.; Chen, L.; Xu, S.; Jiang, T.; Zhang, C.; Cheng, G.; Chen, X.; Kong, D.; Wang, Y.; Zhang, T.; Zi, J.; Wei, W.; Gao, Y.; Zhen, B.; Xiong, Z.; Wu, S.; Yang, P.; Wang, Q.; Wen, B.; He, F.; Xu, P.; Liu, S. Tissue-Based Proteogenomics Reveals That Human Testis Endows Plentiful Missing Proteins. J. Proteome Res. 2015, 14 (9), 3583-3594. 
(21) Duek, P.; Gateau, A.; Bairoch, A.; Lane, L. Exploring the Uncharacterized Human Proteome Using NeXtProt. J. Proteome Res. 2018, 17 (12), 4211-4226.

https://doi.org/10.1021/acs.jproteome.8b00537.

(22) Dacheux, J.-L.; Dacheux, F. New Insights into Epididymal Function in Relation to Sperm Maturation. REPRODUCTION 2014, 147 (2), R27-R42.

(23) Melaine, N.; Com, E.; Bellaud, P.; Guillot, L.; Lagarrigue, M.; Morrice, N. A.; Guével, B.; Lavigne, R.; Velez de la Calle, J.-F.; Dojahn, J.; Pineau, C. Deciphering the Dark Proteome: Use of the Testis and Characterization of Two Dark Proteins. J. Proteome Res. 2018, 17 (12), 4197-4210.

(24) Xia, M.; Xia, J.; Yang, D.; Liu, M.; Niu, C.; Shen, X.; Sun, H.; Zheng, Y. [Preparation and Application of Rabbit Polyclonal Antibody against Mouse Tex33]. Chinese J. Cell. Mol. Immunol. 2018, 34 (7), 643-649.

(25) Lin, S.-R.; Li, Y.-C.; Luo, M.-L.; Guo, H.; Wang, T.-T.; Chen, J.-B.; Ma, Q.; Gu, Y.L.; Jiang, Z.-M.; Gui, Y.-T. Identification and Characteristics of the Testes-Specific Gene, Ccdc38, in Mice. Mol. Med. Rep. 2016, 14 (2), 1290-1296.

(26) Beurois, J.; Martinez, G.; Cazin, C.; Kherraf, Z.-E.; Amiri-Yekta, A.; Thierry-Mieg, N.; Bidart, M.; Petre, G.; Satre, V.; Brouillet, S.; Touré, A.; Arnoult, C.; Ray, P. F.; Coutton, C. CFAP70 Mutations Lead to Male Infertility Due to Severe AsthenoTeratozoospermia. A Case Report. Hum. Reprod. 2019, 34 (10), 2071-2079.

(27) Li, Z.-Z.; Zhao, W.-L.; Wang, G.-S.; Gu, N.-H.; Sun, F. The Novel Testicular Enrichment Protein Cfap58 Is Required for Notch-Associated Ciliogenesis. Biosci. Rep. 2020, 40 (1). https://doi.org/10.1042/BSR20192666.

(28) Wu, X.-L.; Yun, D.-M.; Gao, S.; Liang, A.-J.; Duan, Z.-Z.; Wang, H.-S.; Wang, G.-S.; Sun, F. The Testis-Specific Gene 1700102P08Rik Is Essential for Male Fertility. Mol. Reprod. Dev. 2020, 87 (2), 231-240.

(29) Kang, Y.; Xie, H.; Zhao, C. Ankrd45 Is a Novel Ankyrin Repeat Protein Required for Cell Proliferation. Genes (Basel). 2019, 10 (6). https://doi.org/10.3390/genes 10060462.

(30) Taschner, M.; Lorentzen, E. The Intraflagellar Transport Machinery. Cold Spring Harb. Perspect. Biol. 2016, 8 (10), a028092.

(31) Chapple, C. E.; Robisson, B.; Spinelli, L.; Guien, C.; Becker, E.; Brun, C. Extreme Multifunctional Proteins Identified from a Human Protein Interaction Network. Nat. Commun. 2015, 6 (May), 7412.

(32) Deane, J. A.; Cole, D. G.; Seeley, E. S.; Diener, D. R.; Rosenbaum, J. L. Localization of Intraflagellar Transport Protein IFT52 Identifies Basal Body Transitional Fibers as the Docking Site for IFT Particles. Curr. Biol. 2001, 11 (20), 1586-1590.

(33) Fan, Z.-C.; Behal, R. H.; Geimer, S.; Wang, Z.; Williamson, S. M.; Zhang, H.; Cole, D. G.; Qin, H. Chlamydomonas IFT70/CrDYF-1 Is a Core Component of IFT Particle Complex B and Is Required for Flagellar Assembly. Mol. Biol. Cell 2010, 21 (15), 2696-2706.

(34) Ou, G.; Koga, M.; Blacque, O. E.; Murayama, T.; Ohshima, Y.; Schafer, J. C.; Li, C.; Yoder, B. K.; Leroux, M. R.; Scholey, J. M. Sensory Ciliogenesis in Caenorhabditis Elegans : Assignment of IFT Components into Distinct Modules Based on Transport and Phenotypic Profiles. Mol. Biol. Cell 2007, 18 (5), 1554-1569. 
(35) De Lima Morais, D. A.; Fang, H.; Rackham, O. J. L.; Wilson, D.; Pethica, R.; Chothia, C.; Gough, J. SUPERFAMILY 1.75 Including a Domain-Centric Gene Ontology Method. Nucleic Acids Res. 2011, 39 (SUPPL. 1), 427-434.

(36) Rose, A.; Meier, I. Scaffolds, Levers, Rods and Springs: Diverse Cellular Functions of Long Coiled-Coil Proteins. Cell. Mol. Life Sci. 2004, 61 (16), 1996-2009.

(37) van Dam, T. J.; Wheway, G.; Slaats, G. G.; Huynen, M. A.; Giles, R. H. The SYSCILIA Gold Standard (SCGSv1) of Known Ciliary Components and Its Applications within a Systems Biology Consortium. Cilia 2013, 2 (1), 7.

(38) Gupta, G. D.; Coyaud, É.; Gonçalves, J.; Mojarad, B. A.; Liu, Y.; Wu, Q.; Gheiratmand, L.; Comartin, D.; Tkach, J. M.; Cheung, S. W. T.; Bashkurov, M.; Hasegan, M.; Knight, J. D.; Lin, Z. Y.; Schueler, M.; Hildebrandt, F.; Moffat, J.; Gingras, A. C.; Raught, B.; Pelletier, L. A Dynamic Protein Interaction Landscape of the Human Centrosome-Cilium Interface. Cell 2015, 163 (6), 1484-1499.

(39) Nigg, E. A.; Raff, J. W. Centrioles, Centrosomes, and Cilia in Health and Disease. Cell 2009, 139 (4), 663-678.

(40) Tollenaere, M. A. X.; Mailand, N.; Bekker-Jensen, S. Centriolar Satellites: Key Mediators of Centrosome Functions. Cell. Mol. Life Sci. 2015, 72 (1), 11-23.

(41) Odabasi, E.; Batman, U.; Firat-Karalar, E. N. Unraveling the Mysteries of Centriolar Satellites: Time to Rewrite the Textbooks about the Centrosome/Cilium Complex. Mol. Biol. Cell 2020, 31 (9), 866-872.

(42) Avidor-Reiss, T.; Khire, A.; Fishman, E. L.; Jo, K. H. Atypical Centrioles during Sexual Reproduction. Front. cell Dev. Biol. 2015, 3, 21.

(43) Avidor-Reiss, T.; Mazur, M.; Fishman, E. L.; Sindhwani, P. The Role of Sperm Centrioles in Human Reproduction - The Known and the Unknown. Front. Cell Dev. Biol. 2019, 7. https://doi.org/10.3389/fcell.2019.00188.

(44) Lopes, C. A. M.; Prosser, S. L.; Romio, L.; Hirst, R. A.; O’Callaghan, C.; Woolf, A. S.; Fry, A. M. Centriolar Satellites Are Assembly Points for Proteins Implicated in Human Ciliopathies, Including Oral-Facial-Digital Syndrome 1. J. Cell Sci. 2011, 124 (Pt 4), 600-612.

(45) Tang, Z.; Lin, M. G.; Stowe, T. R.; Chen, S.; Zhu, M.; Stearns, T.; Franco, B.; Zhong, Q. Autophagy Promotes Primary Ciliogenesis by Removing OFD1 from Centriolar Satellites. Nature 2013, 502 (7470), 254-257.

(46) Kodani, A.; Yu, T. W.; Johnson, J. R.; Jayaraman, D.; Johnson, T. L.; Al-Gazali, L.; Sztriha, L.; Partlow, J. N.; Kim, H.; Krup, A. L.; Dammermann, A.; Krogan, N. J.; Walsh, C. A.; Reiter, J. F. Centriolar Satellites Assemble Centrosomal Microcephaly Proteins to Recruit CDK2 and Promote Centriole Duplication. Elife 2015, 4. https://doi.org/10.7554/eLife.07519.

(47) Guo, J.; Grow, E. J.; Mlcochova, H.; Maher, G. J.; Lindskog, C.; Nie, X.; Guo, Y.; Takei, Y.; Yun, J.; Cai, L.; Kim, R.; Carrell, D. T.; Goriely, A.; Hotaling, J. M.; Cairns, B. R. The Adult Human Testis Transcriptional Cell Atlas. Cell Res. 2018, 28 (12), 1141-1157.

(48) Netherton, J. K.; Hetherington, L.; Ogle, R. A.; Velkov, T.; Baker, M. A. Proteomic Analysis of Good- and Poor-Quality Human Sperm Demonstrates That Several 
Proteins Are Routinely Aberrantly Regulated. Biol. Reprod. 2018, 99 (2), 395-408.

(49) Marley, A.; von Zastrow, M. A Simple Cell-Based Assay Reveals That Diverse Neuropsychiatric Risk Genes Converge on Primary Cilia. PLoS One 2012, 7 (10), e46647.

(50) Breslow, D. K.; Hoogendoorn, S.; Kopp, A. R.; Morgens, D. W.; Vu, B. K.; Kennedy, M. C.; Han, K.; Li, A.; Hess, G. T.; Bassik, M. C.; Chen, J. K.; Nachury, M. V. A CRISPR-Based Screen for Hedgehog Signaling Provides Insights into Ciliary Function and Ciliopathies. Nat. Genet. 2018, 50 (3), 460-471.

(51) Lerer-Goldshtein, T.; Bel, S.; Shpungin, S.; Pery, E.; Motro, B.; Goldstein, R. S.; BarSheshet, S. I.; Breitbart, H.; Nir, U. TMF/ARA160: A Key Regulator of Sperm Development. Dev. Biol. 2010, 348 (1), 12-21.

(52) Berruti, G.; Paiardi, C. Acrosome Biogenesis: Revisiting Old Questions to Yield New Insights. Spermatogenesis 2011, 1 (2), 95-98.

(53) Abou-Haila, A.; Tulsiani, D. R. Mammalian Sperm Acrosome: Formation, Contents, and Function. Arch. Biochem. Biophys. 2000, 379 (2), 173-182.

(54) Elkis, Y.; Bel, S.; Rahimi, R.; Lerer-Goldstein, T.; Levin-Zaidman, S.; Babushkin, T.; Shpungin, S.; Nir, U. TMF/ARA160 Governs the Dynamic Spatial Orientation of the Golgi Apparatus during Sperm Development. PLoS One 2015, 10 (12), e0145277.

(55) Galvez, T.; Gilleron, J.; Zerial, M.; O’Sullivan, G. A. SnapShot: Mammalian Rab Proteins in Endocytic Trafficking. Cell 2012, 151 (1), 234-234.e2.

(56) Ward, W. S.; Coffey, D. S. DNA Packaging and Organization in Mammalian Spermatozoa: Comparison with Somatic Cells. Biol. Reprod. 1991, 44 (4), 569-574.

(57) Rousseaux, S.; Reynoird, N.; Escoffier, E.; Thevenon, J.; Caron, C.; Khochbin, S. Epigenetic Reprogramming of the Male Genome during Gametogenesis and in the Zygote. Reprod. Biomed. Online 2008, 16 (4), 492-503.

(58) McLay, D.; Clarke, H. Remodelling the Paternal Chromatin at Fertilization in Mammals. Reproduction 2003, 625-633.

(59) Ajduk, A.; Yamauchi, Y.; Ward, M. A. Sperm Chromatin Remodeling after Intracytoplasmic Sperm Injection Differs from That of In Vitro Fertilization1. Biol. Reprod. 2006, 75 (3), 442-451.

(60) Amaral, A.; Castillo, J.; Ramalho-Santos, J.; Oliva, R. The Combined Human Sperm Proteome: Cellular Pathways and Implications for Basic and Clinical Science. Hum. Reprod. Update 2014, 20 (1), 40-62.

(61) Tropberger, P.; Pott, S.; Keller, C.; Kamieniarz-Gdula, K.; Caron, M.; Richter, F.; Li, G.; Mittler, G.; Liu, E. T.; Bühler, M.; Margueron, R.; Schneider, R. Regulation of Transcription through Acetylation of H3K122 on the Lateral Surface of the Histone Octamer. Cell 2013, 152 (4), 859-872.

(62) Spector, D. L.; Lamond, A. I. Nuclear Speckles. Cold Spring Harb. Perspect. Biol. 2011, 3 (2). https://doi.org/10.1101/cshperspect.a000646.

(63) Phair, R. D.; Misteli, T. High Mobility of Proteins in the Mammalian Cell Nucleus. Nature 2000, 404 (6778), 604-609. 
(64) Simpson, A. J. G.; Caballero, O. L.; Jungbluth, A.; Chen, Y.-T.; Old, L. J. Cancer/Testis Antigens, Gametogenesis and Cancer. Nat. Rev. Cancer 2005, 5 (8), $615-625$.

(65) van der Bruggen, P.; Traversari, C.; Chomez, P.; Lurquin, C.; De Plaen, E.; Van den Eynde, B.; Knuth, A.; Boon, T. A Gene Encoding an Antigen Recognized by Cytolytic T Lymphocytes on a Human Melanoma. Science 1991, 254 (5038), 1643-1647.

(66) Osterlund, C.; Töhönen, V.; Forslund, K. O.; Nordqvist, K. Mage-B4, a Novel Melanoma Antigen (MAGE) Gene Specifically Expressed during Germ Cell Differentiation. Cancer Res. 2000, 60 (4), 1054-1061.

(67) Amano, M.; Nakayama, M.; Kaibuchi, K. Rho-Kinase/ROCK: A Key Regulator of the Cytoskeleton and Cell Polarity. Cytoskeleton (Hoboken). 2010, 67 (9), 545-554.

(68) Lui, W.-Y.; Lee, W. M.; Cheng, C. Y. Rho GTPases and Spermatogenesis. Biochim. Biophys. Acta 2003, 1593 (2-3), 121-129.

(69) Com, E.; Melaine, N.; Chalmel, F.; Pineau, C. Proteomics and Integrative Genomics for Unraveling the Mysteries of Spermatogenesis: The Strategies of a Team. $J$. Proteomics 2014, 107, 128-143.

(70) Blake, J. A.; Bult, C. J.; Eppig, J. T.; Kadin, J. A.; Richardson, J. E.; Mouse Genome Database Group. The Mouse Genome Database Genotypes::Phenotypes. Nucleic Acids Res. 2009, 37 (Database issue), D712-9.

(71) Eppig, J. T.; Blake, J. A.; Bult, C. J.; Kadin, J. A.; Richardson, J. E. The Mouse Genome Database (MGD): Comprehensive Resource for Genetics and Genomics of the Laboratory Mouse. Nucleic Acids Res. 2012, 40 (D1), D881-D886.

(72) Dickinson, M. E.; Flenniken, A. M.; Ji, X.; Teboul, L.; Wong, M. D.; White, J. K.; Meehan, T. F.; Weninger, W. J.; Westerberg, H.; Adissu, H.; Baker, C. N.; Bower, L.; Brown, J. M.; Caddle, L. B.; Chiani, F.; Clary, D.; Cleak, J.; Daly, M. J.; Denegre, J. M.; Doe, B.; Dolan, M. E.; Edie, S. M.; Fuchs, H.; Gailus-Durner, V.; Galli, A.; Gambadoro, A.; Gallegos, J.; Guo, S.; Horner, N. R.; Hsu, C.-W.; Johnson, S. J.; Kalaga, S.; Keith, L. C.; Lanoue, L.; Lawson, T. N.; Lek, M.; Mark, M.; Marschall, S.; Mason, J.; McElwee, M. L.; Newbigging, S.; Nutter, L. M. J.; Peterson, K. A.; Ramirez-Solis, R.; Rowland, D. J.; Ryder, E.; Samocha, K. E.; Seavitt, J. R.; Selloum, M.; Szoke-Kovacs, Z.; Tamura, M.; Trainor, A. G.; Tudose, I.; Wakana, S.; Warren, J.; Wendling, O.; West, D. B.; Wong, L.; Yoshiki, A.; Wurst, W.; MacArthur, D. G.; Tocchini-Valentini, G. P.; Gao, X.; Flicek, P.; Bradley, A.; Skarnes, W. C.; Justice, M. J.; Parkinson, H. E.; Moore, M.; Wells, S.; Braun, R. E.; Svenson, K. L.; de Angelis, M. H.; Herault, Y.; Mohun, T.; Mallon, A.-M.; Henkelman, R. M.; Brown, S. D. M.; Adams, D. J.; Lloyd, K. C. K.; McKerlie, C.; Beaudet, A. L.; Bućan, M.; Murray, S. A. High-Throughput Discovery of Novel Developmental Phenotypes. Nature 2016, 537 (7621), 508-514.

(73) Bontems, F.; Fish, R. J.; Borlat, I.; Lembo, F.; Chocu, S.; Chalmel, F.; Borg, J.-P.; Pineau, C.; Neerman-Arbez, M.; Bairoch, A.; Lane, L. C2orf62 and TTC17 Are Involved in Actin Organization and Ciliogenesis in Zebrafish and Human. PLoS One 2014, 9 (1), e86476.

(74) Arafat, M.; Harlev, A.; Har-Vardi, I.; Levitas, E.; Priel, T.; Gershoni, M.; Searby, C.; Sheffield, V. C.; Lunenfeld, E.; Parvari, R. Mutation in CATIP (C2orf62) Causes 
Oligoteratoasthenozoospermia by Affecting Actin Dynamics. J. Med. Genet. 2020, jmedgenet-2019-106825.

(75) Livera, G.; Delbes, G.; Pairault, C.; Rouiller-Fabre, V.; Habert, R. Organotypic Culture, a Powerful Model for Studying Rat and Mouse Fetal Testis Development. Cell Tissue Res. 2006, 324 (3), 507-521. 


\section{TOC graphic}

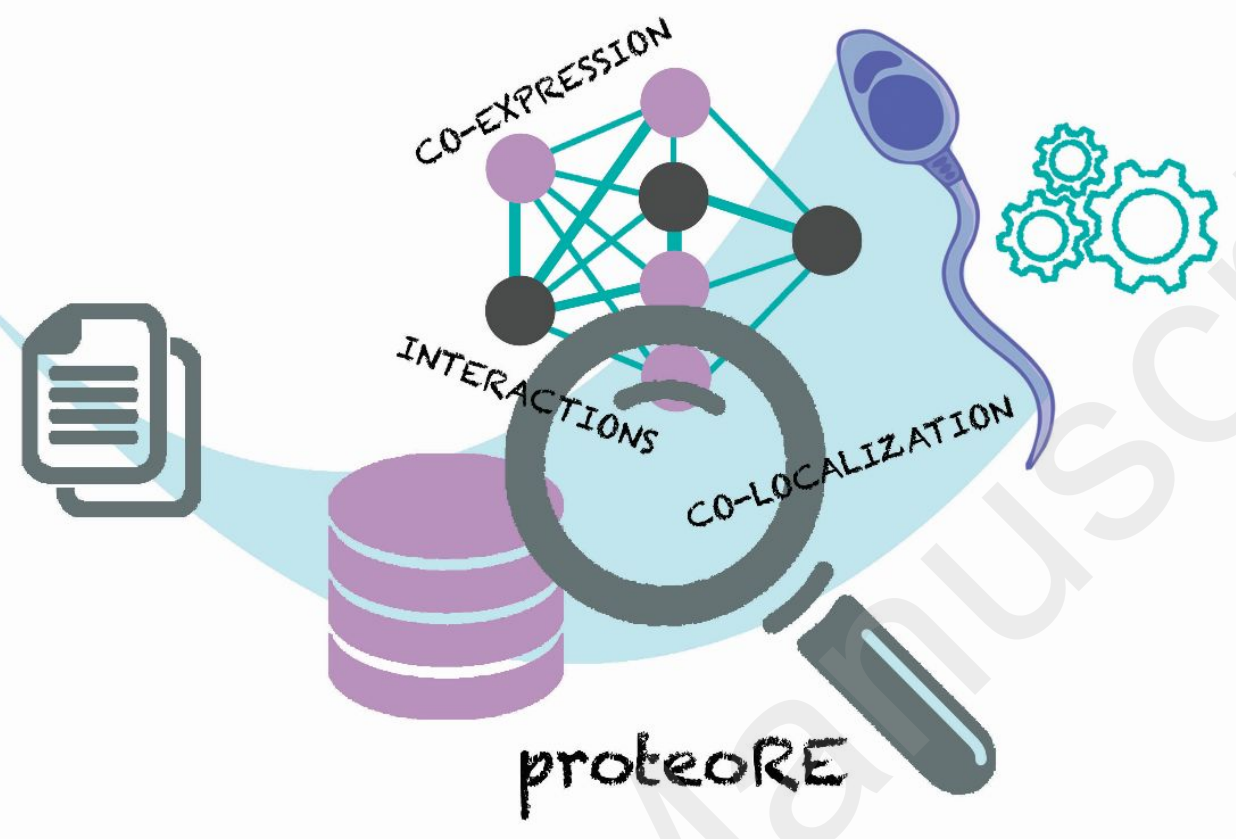




\section{Figure 1.}

Building a core proteome of the human male reproductive system: $\mathbf{2 , 7 1 4}$ protein entries with elevated expression in male tissues (HPA)

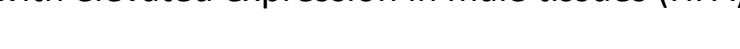
proteome (literature survey):

Establishing the functionally unannotated human male tissue proteome: $\mathbf{4 1 2}$ uPE1 (neXtProt)

Putting the male tissue UPE1 proteins in their cellular and molecular context (protein complexes (hu.MAP), co-expression (HPA), co-localization (HPA, neXtProt)): 41 UPE1 mapped onto 37 protein complexes

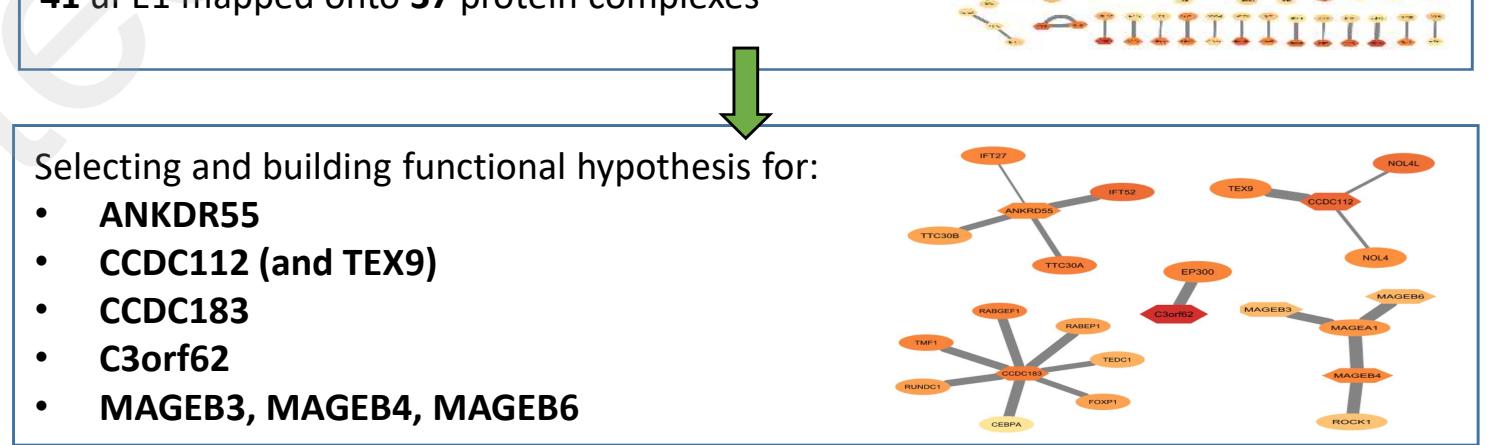




\section{${ }_{5}^{4}$ Figure 2 .}

6

2

3

14
15

16

17

18

19

23

25

27

28
29

30

31

35

39

46

47

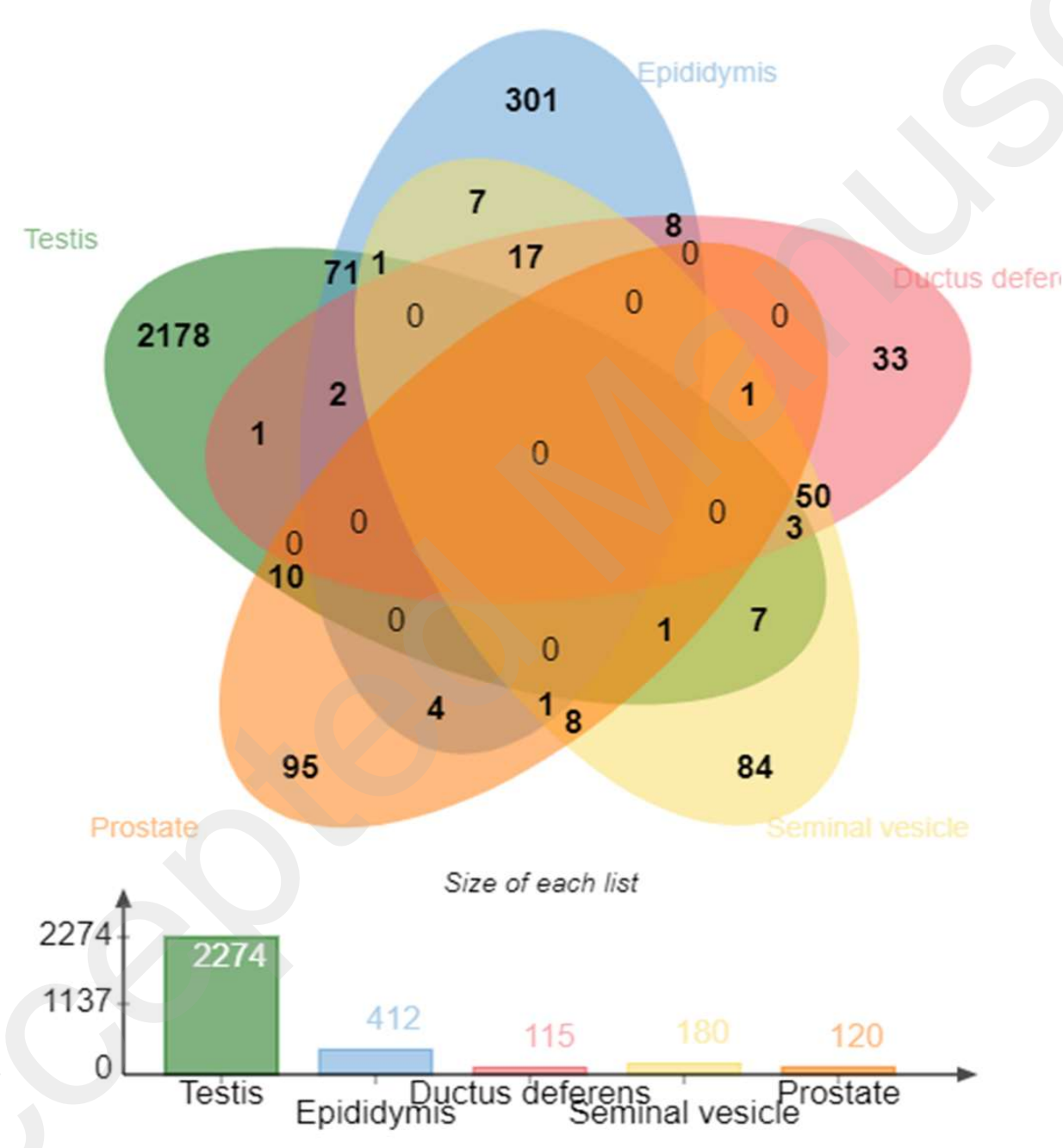


覃igure 3.

6

7

8

9

10

11

12

13

14

15

16

17

18

19

20

21

22

23

24

25

26

27

28

29

30

31

32

33

34

35

36

37

38

39

40

41

42

43

44

45

46

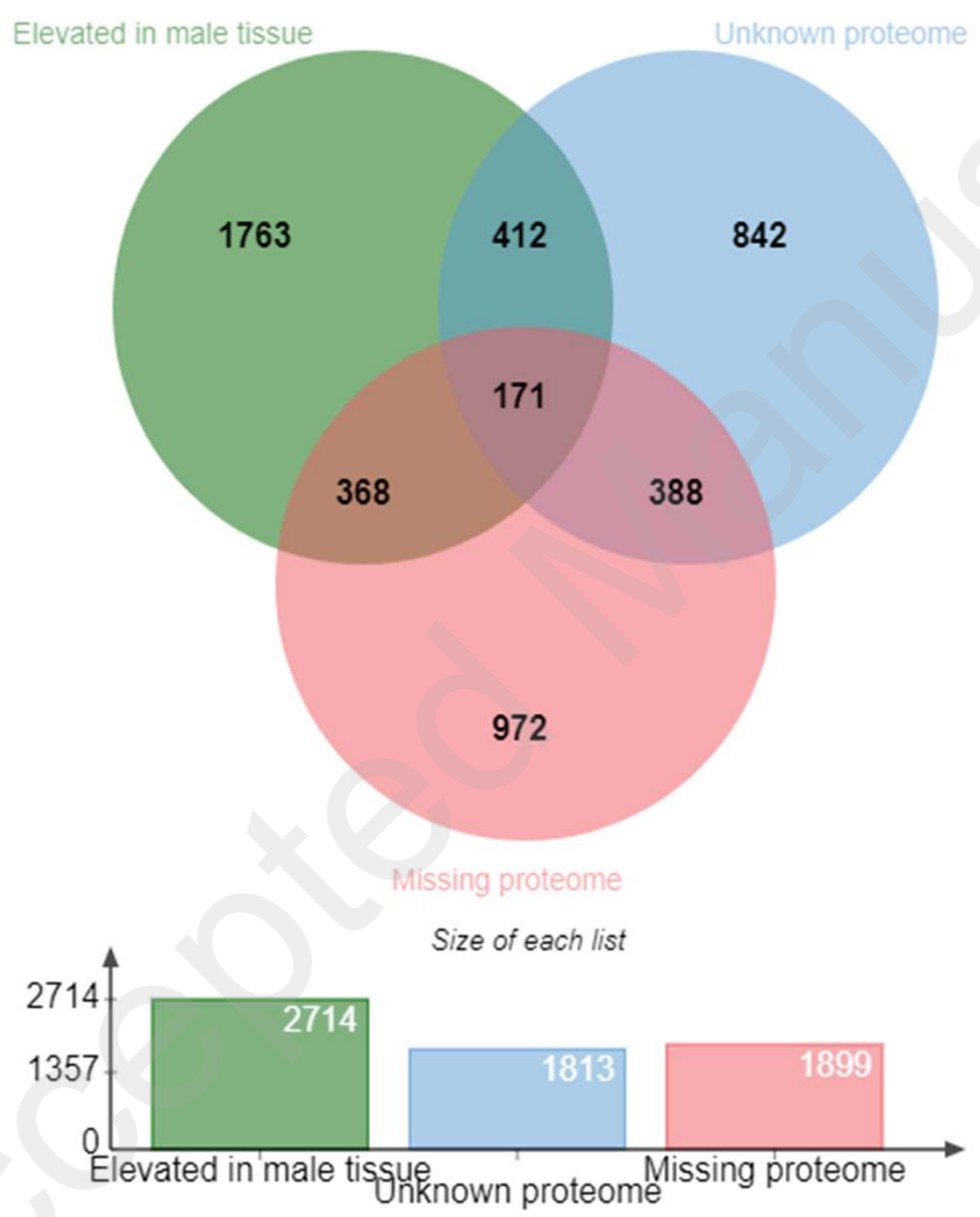


1
2
3
4

हुgigure 4.

6
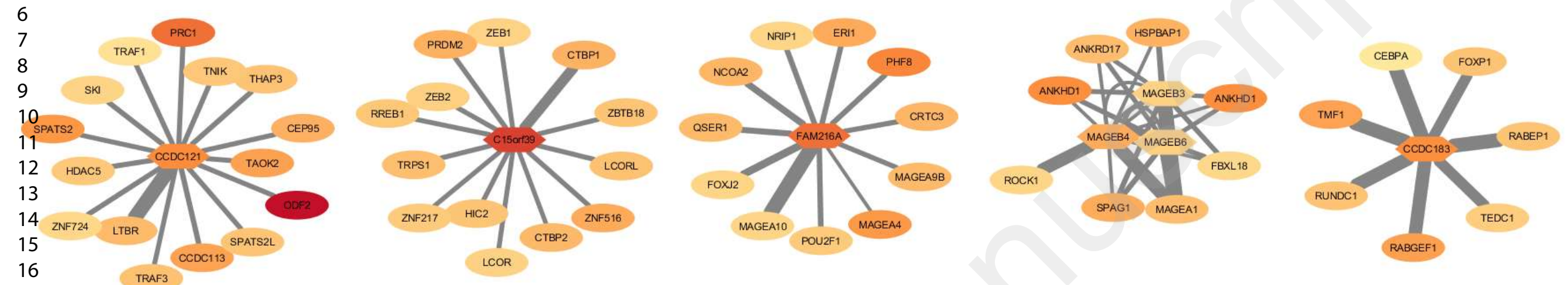

16
17

18

19

20
21
22
23
24
25

26

27

28

29
30

$31_{F}$

32
33

33
34

34
35

35
36

37

38

39

40
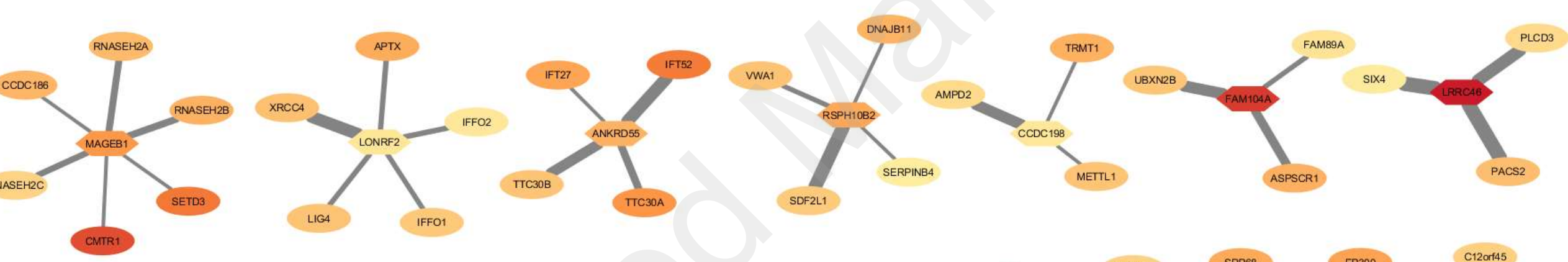

42

43

44

45

46

47 
Figure 5.

6

8

9

10

11

12

13

14

15

16

17

18

19

20

21

22

23

24

25

26

27

28

29

30

31

32

33

34

35

36

37

38

39

40

41

42

43

45

46
47

A.

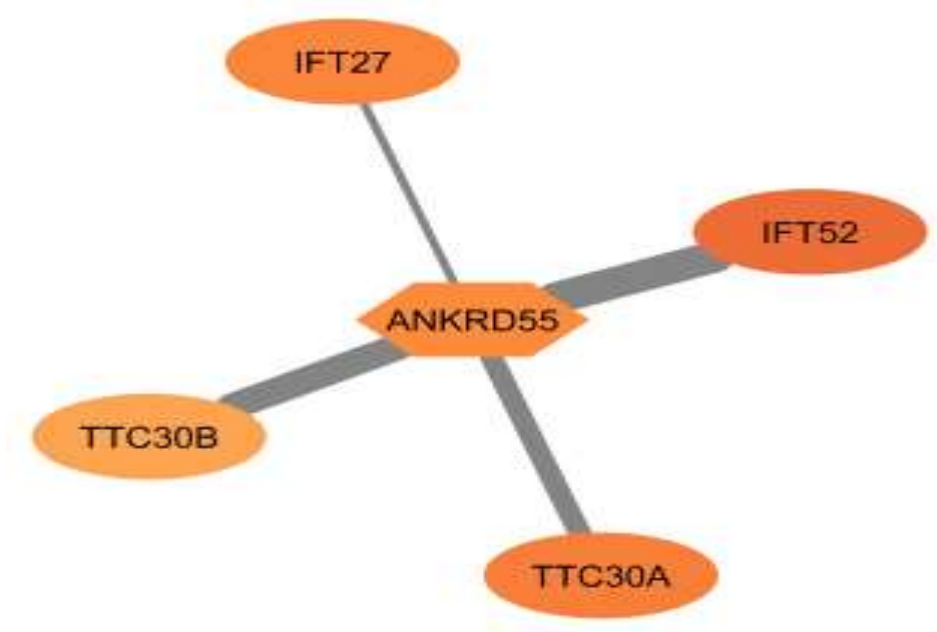

C.

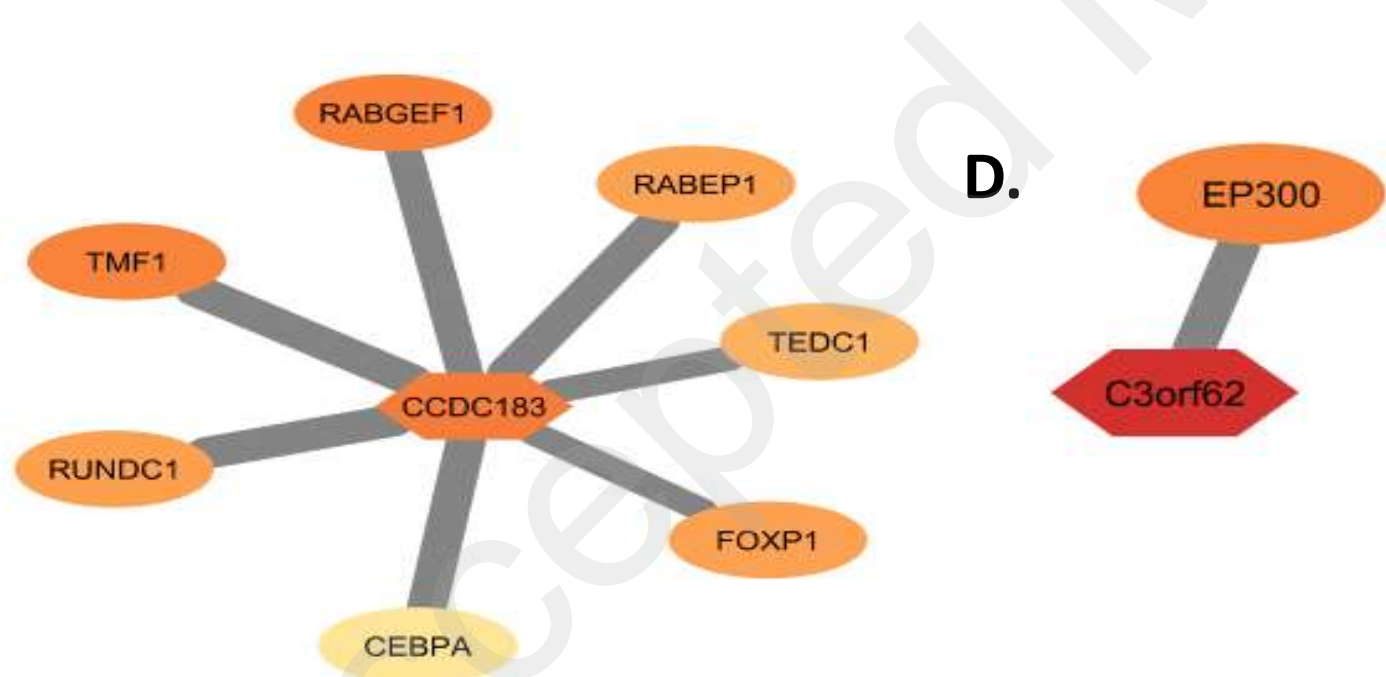

B.
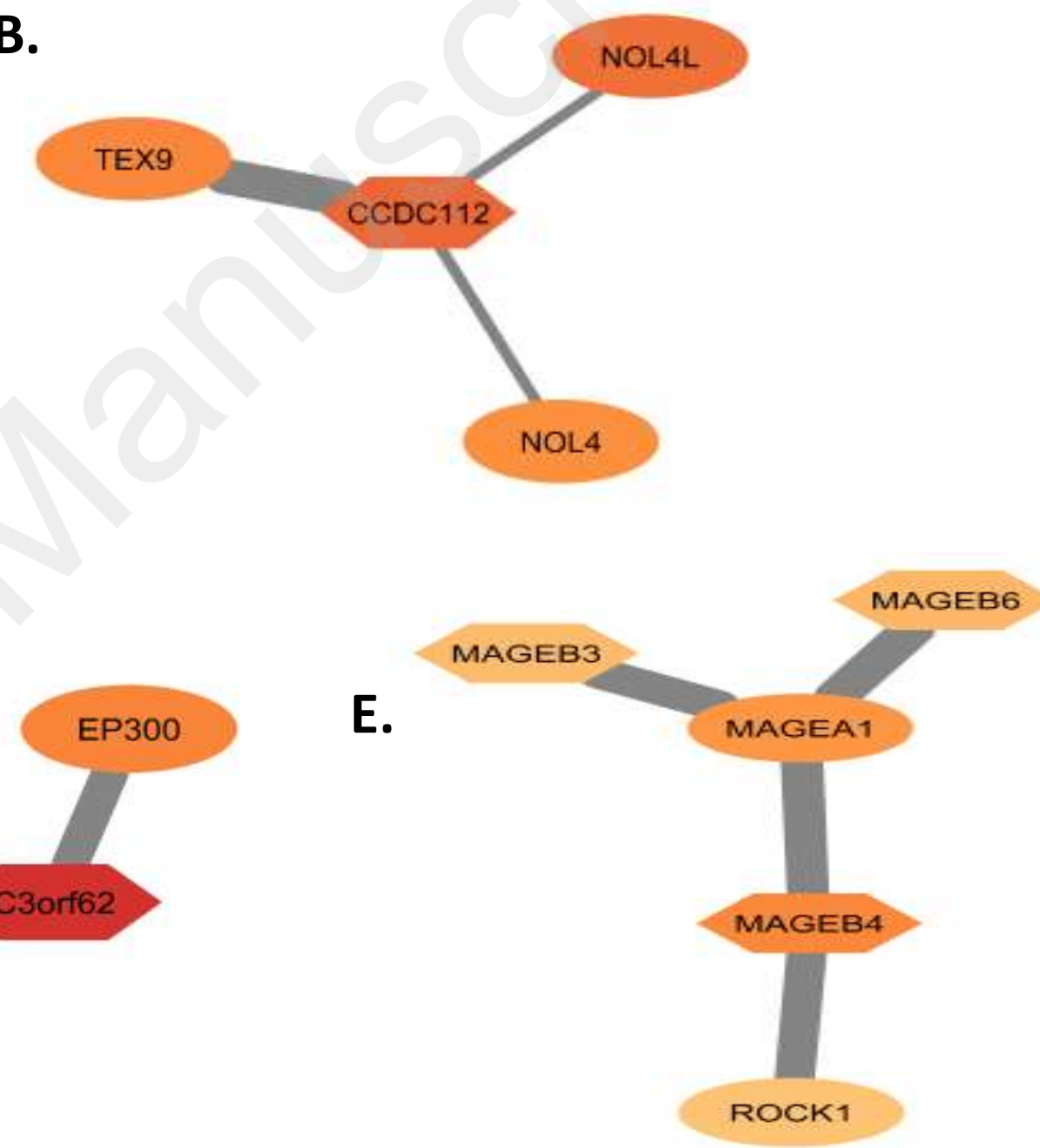


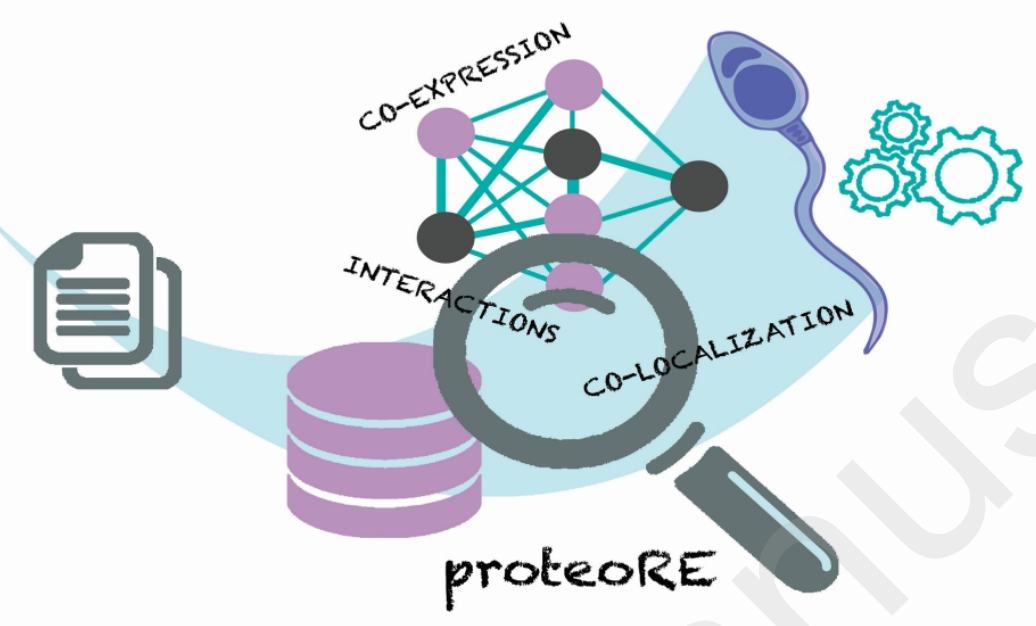

$604 \times 403 \mathrm{~mm}(96 \times 96 \mathrm{DPI})$ 